\title{
Molecular-level electrochemical doping for fine discrimination of volatile organic compounds in organic chemiresistors
}

Received 00th January 20xx, Accepted 00th January 20xx DOI: $10.1039 / \times 0 \times x 00000 x$

\author{
Sooncheol Kwon ${ }^{*}$, Yusin Pak ${ }^{b}$, Bongseong Kim ${ }^{d}$, Byoungwook Park ${ }^{c}$, Jehan Kim ${ }^{e}$, Geunjin Kim ${ }^{d}$, Yong- \\ Ryun Joc, Saurav Limbuf, Katherine Stewartf, Hyeonghun Kim c', Bong-Joong Kim ${ }^{c}$, Soo-Young Jang ${ }^{a}$, \\ Hongkyu Kang ${ }^{a}$, Jung-Wook Min ${ }^{g}$, Ji-Seon Kim ${ }^{*}$, Gun Young Jung ${ }^{* *}$ and Kwanghee Lee ${ }^{a c *}$
}

\begin{abstract}
Printable organic sensors fabricated from solution-processed $\pi$-conjugated polymers ( $\pi$-CPs) are promising candidates to detect volatile organic compounds (VOCs) due to the intriguing physical, chemical and electronic properties of $\pi$-CPs. These devices, often termed organic chemiresistors, require good sensing capabilities to transduce stimuli from specific VOCs at low concentrations into analytical electric signals. However, discriminating such VOCs using organic chemiresistors has proven very challenging. Herein, we report that the molecular-level electrochemical doping of $\pi$-CPs by solid-state ionic liquids (SIL) significantly improves their electrical conductivity $\left(\sim 10^{-1} \mathrm{~S} / \mathrm{cm}\right)$ and selective VOC interactions, which can be manipulated through different $\pi$-CPs:SIL blend ratio. Those characteristics enable the fine discrimination of VOCs at concentrations in the parts-per-billion $(\mathrm{ppb})$ range under low power consumption $(<0.1 \mu \mathrm{W})$ and room temperature conditions. Our result provides a new opportunity for developing highly sensitive and selective VOC monitoring platforms technology that are printable on large-area, wearable, flexible and transparent substrates.
\end{abstract}

\section{Introduction}

Instead of large stand-alone analytical systems (e.g., mass spectrometers, chromatographs, infrared spectrometers) $)^{1-3}$, chemiresistors with semiconducting materials are emerging as promising technology for detecting volatile organic compounds (VOCs), which can be used to advanced sensor applications, such as non-invasive discrimination for medical diagnosis. For example, the chemiresistors with highly conducting metal oxides or nanoparticles have been found to enable the detection of a few representative VOCs (i.e., acetone and toluene) in exhaled breath to successfully identify a medical condition $^{4-6}$. In addition, the chemiresistors can also distinguish some specific VOCs (i.e., 2-propanol and chlorobenzene) with levels of several hundred parts per billion ( $p p b)$ in specific

\footnotetext{
a. Research Institute for Solar and Sustainable Energies (RISE), Gwangju Institute of Science and Technology (GIST), Gwangju 500-712, Republic of Korea. E-mail: kwansc@gist.ac.kr

b. Sensor System Research Center (SSRC), Korea Institute of Science and Technology (KIST), Seoul 02792, Republic of Korea.

School of Materials Science and Engineering (SMSE), Gwangju Institute of Science and Technology (GIST), Gwangju 500-712, Republic of Korea. E-mail: klee@gist.ac.kr

d. Heeger Center for Advanced Materials (HCAM), Gwangju Institute of Science and Technology (GIST), Gwangju 500-712, Republic of Korea.

e. Pohang Accelerator Laboratory, Pohang University of Science and Technology, Pohang 37673, Republic of Korea.

f. Department of Physics and Centre for Plastic Electronics, Imperial College London, London, SW7 2AZ, United Kingdom.

g. Physical Sciences and Engineering Division, King Abdullah University of Science and Technology (KAUST), Thuwal, Kingdom of Saudi Arabia

+Electronic Supplementary Information (ESI) available: [details of any supplementary information available should be included here]. See DOI: $10.1039 / x 0 x x 00000 x$
}

location/site for smart home care ${ }^{7-10}$. However, such chemiresistors often require complex fabrication methods on a rigid substrate and/or tough operation conditions such as high temperature $\left(>300^{\circ} \mathrm{C}\right)$, which make them difficult to combine with other electronic applications ${ }^{7,8}$.

In contrast to their inorganic counterparts, solutionprocessed organic chemiresistors with $\pi$-conjugated polymers $(\pi$-CPs) are attractive as a promising platform technology for overcoming those challenges because $\pi$-electron distribution and/or structural orientation of organic polymers can be readily influenced by the local dielectric environment change from nearby VOCs without the need of harsh conditions ${ }^{11,12}$. Despite many efforts to improve the detection level of organic chemiresistors using gate-induced electrostatics and/or chemical doping of the $\pi$-CPs, they still suffer from low VOCsensing capabilities, (e.g., low selectivity, sensitivity, speed, and stability), most of which are inherent to a low electrical conductivity $\left(<10^{-3} \mathrm{~S} / \mathrm{cm}\right)$ and limited device geometry ${ }^{13-15}$. For example, three-terminal organic field effect transistor (OFET) architecture with uniform ultrathin polymer film deposited by a wire-wound bar-coating method have been used to improve their electrical conductivity; however, this device geometry often deteriorate the ultratrace recognition of VOCs for the desirable sensing applications because it has a poor VOC diffusion into the buried interface between $\pi$-CPs and the gate dielectric layer ${ }^{16}$. The key challenge is to develop a stable doping method on the $\pi$-CPs to improve their electrical properties throughout the bulk film, thereby establishing a two-terminal device architecture to enable the fine discrimination of selective VOC interaction at the film surface. 
Recently, an electrochemical doping of $\pi$-CPs using electrolytes consisting of two asymmetrical ions of opposite charges (e.g., liquid-state ionic liquids at room temperature) has been considered as an alternative approach that may meet the specific requirements for desirable organic chemiresistors ${ }^{17-19}$. The coupling between the electronic charges and the ionic charges along the polymer backbones induces sufficient charge carriers within the source/drain channel, thus leading to metallic conduction in the $\pi-\mathrm{CPs}^{20,21}$. However, their intermolecular interactions between $\pi$-CPs and liquid-state ionic liquids are hindered by a phase segregation due to the large difference of their surface energy ${ }^{22-24}$. Moreover, the morphology with large phase separation may lead to an unstable ion diffusion and turn-on, consequently resulting in poor selective VOC interaction ${ }^{25}$. Therefore, establishing simpler two-terminal organic chemiresistors (TOCs) utilizing a molecular-level blend system of $\pi$-CPs and favorable ionic liquids would be of great interest with high potential impact. This approach can bring advantages such as (i) an enlarged interfacial area between $\pi$-CPs and ionic liquids throughout the bulk film can be achieved, (ii) a primary electrochemical doping of $\pi$-CPs by the ionic liquid can efficiently modulate their electrical conductivity without the need for gate bias, and (iii) the blend ratio between $\pi$-CPs and ionic liquids can influence the level of electrochemical doping of $\pi$-CPs and the resultant nanoscale morphology (and consequently improve a selective VOC interaction).

Herein, we demonstrate that TOCs with a blend of $\pi$-CPs and a chemically modified solid-state ionic liquid provide an enlarged interfacial area, enabling stable and high-level electrochemical doping of $\pi$-CPs at room temperature, and hence allowing sub-ppm-level detection of various VOCs (i.e., acetone, 2-propanol, toluene and chlorobenzene) under ultralow power consumption $(<0.1 \mu \mathrm{W})$. Based on a combination of in-situ $X$-ray diffraction and advanced electrical analysis, we attribute that these fine discriminatory abilities of TOCs are originated from a change of electrochemical doping efficiency by a selective interactions between ionic liquid and VOCs at the film surface.

\section{Experimental}

\section{Material synthesis}

The high-purity semiconducting polymer DT-PDTT2T-TT was synthesized by 1-Materials, Chemscitech, Inc., QC, Canada, and was used as received. The average Mw of DT-PDTT2T-TT was 51 $\mathrm{kg} \cdot \mathrm{mol}-1$. Synthesis of $\left[\mathrm{C}_{1} \mathrm{C}_{12} \mathrm{IM}^{+}\right]\left[\mathrm{PF}_{6}{ }^{-}\right]$: 1-Methylimidazole (99\%), 1-bromododecane (97\%), ammonium hexafluorophosphate (99.99\%), toluene, ethyl acetate and dichloromethane were purchased from Sigma Aldrich. 1Methylimidazole $(6 \mathrm{~g}, 73.0 \mathrm{mmol})$ and 1-bromododecane (20 g, $80.2 \mathrm{mmol}$ ) were dissolved in dry toluene $(80 \mathrm{~mL})$. The mixture was stirred at $110^{\circ} \mathrm{C}$ under nitrogen for $72 \mathrm{~h}$. After the solvent was removed by rotary evaporation, the crude product was washed with cold ethyl acetate $\left(-30{ }^{\circ} \mathrm{C}, 100 \mathrm{~mL}\right)$, and $21.5 \mathrm{~g}$ of product was obtained as a white solid in a yield of $89.0 \%$. $\left[\mathrm{C}_{1} \mathrm{C}_{12} \mathrm{IM}^{+}\right]\left[\mathrm{PF}_{6}^{-}\right](14.4 \mathrm{~g}, 43.4 \mathrm{mmol})$ was dissolved in deionized water $(200 \mathrm{~mL})$, and $\left[\mathrm{NH}_{4}^{+}\right]\left[\mathrm{PF}_{6}^{-}\right](21.25 \mathrm{~g}, 130 \mathrm{mmol})$ was added. The mixture was stirred at room temperature for $72 \mathrm{~h}$. The generated solids were isolated by filtration and washed with water. After dissolving the solids in dichloromethane, $\mathrm{MgSO}_{4}$ was added to remove residual moisture. The mixture was stored at low temperature $\left(-30^{\circ} \mathrm{C}\right)$ for $24 \mathrm{~h}$ and then filtered to remove the $\mathrm{MgSO} 4$ and salt residue. After filtration, the filtrate was concentrated and dried under vacuum. $\left[\mathrm{C}_{1} \mathrm{C}_{12} \mathrm{IM}^{+}\right]\left[\mathrm{PF}_{6}^{-}\right]$was obtained as a white solid in a $94.4 \%$ yield (16.2 g). 1H NMR (400 MHz, DMSO-d6) $\delta[p p m]=0.83(3 \mathrm{H}, \mathrm{t})$, $1.24(18 \mathrm{H}, \mathrm{m}), 1.72(2 \mathrm{H}, \mathrm{t}), 3.84(3 \mathrm{H}, \mathrm{s}), 4.07(2 \mathrm{H}, \mathrm{t}), 7.69(1 \mathrm{H}, \mathrm{s})$, $7.76(1 \mathrm{H}, \mathrm{s}), 9.09(1 \mathrm{H}, \mathrm{s})$. ESI-MS $(\mathrm{m} / \mathrm{z})$ positive ion: 251.2 [cation] ${ }^{+}$, negative ion: 144.9 [anion]-

\section{Solution preparation}

The blended solution of DT-PDTT2T-TT and $\left[\mathrm{C}_{1} \mathrm{C}_{12} \mathrm{IM}^{+}\right]\left[\mathrm{PF}_{6}^{-}\right]$: We directly added $4,12,20,28$ or $40 \mathrm{mg}$ of $\left[\mathrm{C}_{1} \mathrm{C}_{12} \mathrm{IM}^{+}\right]\left[\mathrm{PF}_{6}^{-}\right]$to a 4 $\mathrm{mg} \cdot \mathrm{mL}-1$ DT-PDTT2T-TT solution in chloroform, resulting in final TT:SIL blend ratios of 1:1, 1:3, 1:5, 1:7 and 1:10 (weight by weight, $w / w)$, respectively. The solutions were subsequently stirred in the dark at $45^{\circ} \mathrm{C}$ for more than $2 \mathrm{~h}$ and used without any filtration.

\section{Morphological characterization}

Top-down TEM images of the sample films were collected using a Tecnai G2 F30 S-Twin microscope operated at an acceleration voltage of $300 \mathrm{kV}$. The sample films for the TEM measurements were obtained by peeling the predeposited film $(\mathrm{t} \approx 70 \mathrm{~nm})$ from a glass substrate, and the films were transferred onto carboncoated 200-mesh copper grids (Electron Microscopy Sciences). Structural characterization

Grazing-incidence wide-angle X-ray scattering (GIWAXS) measurements were performed on the 3C-SAXSI beamline at the Pohang Accelerator Laboratory (PAL) using a monochromatized $X$-ray radiation source of $10.55 \mathrm{eV}(\lambda=0.117$ $\mathrm{nm}$ ) and a two-dimensional (2-D) charge-coupled device (CCD) detector (Mar165 CCD). The samples were mounted on a z-axis goniometer equipped with a vacuum chamber ( $\left.10^{-3} \mathrm{Torr}\right)$, and the samples were fixed $0.201 \mathrm{~m}$ away from the CCD detector. The incident angle of each $\mathrm{X}$-ray beam was $0.1^{\circ}$, and the scattering angles were determined from the positions of the reflected $\mathrm{X}$-ray beam relative to the silicon substrate using precalibrated silver behenate.

\section{VOC sensing device fabrication and characterization}

Before the deposition of the prepared DT-PDTT2T-TT and DTPDTT2T-TT:[ $\left.\mathrm{C}_{1} \mathrm{C}_{12} \mathrm{IM}^{+}\right]\left[\mathrm{PF}_{6}{ }^{-}\right]$solutions, heavily doped n-type silicon substrates covered with a 230-nm-thick layer of $\mathrm{SiO}_{2}(L=$ $2.5,5,10$, and $20 \mu \mathrm{m}$, and $W=2000 \mu \mathrm{m})$ or flexible polyethylene naphthalene (PEN) substrates were sonicated in acetone and then isopropyl alcohol for $10 \mathrm{~min}$ each and dried at $100{ }^{\circ} \mathrm{C}$ for $15 \mathrm{~min}$. The DT-PDTT2T-TT and DT-PDTT2T-TT: $\left[\mathrm{C}_{1} \mathrm{C}_{12} \mathrm{IM}^{+}\right]\left[\mathrm{PF}_{6}{ }^{-}\right]$ solutions were deposited onto the substrates at room temperature under ambient conditions, and the final thickness of each was approximately $150 \mathrm{~nm}$, as measured using a Surfcorder ET 3000 instrument. Then, source/drain $\mathrm{Au}$ electrodes were finally deposited on top of the film $(L=20 \mu \mathrm{m}$ and $W=3000 \mu \mathrm{m})$.

The VOC sensing measurement system consisted of four parts: (1) source: gas tanks and regulators; (2) injection: mass- 
flow controller (MFC) and VOC gas generation adiabatic box; (3) gas chamber: probes and a Peltier stage; and (4) analyzer: Keithley 2400 S and a homemade I-V LabVIEW system. Highpurity air (nitrogen:oxygen $=7.9: 2.1,99.999 \%$ dry) was used to match the actual human respiratory environment. The air was passed through two MFCs; in one, the air served as a reference gas for balancing the gas concentration, and in the other, the air served as a carrier gas for carrying the analyte gas into the gas chamber (Nextron Co., Republic of Korea). The analyte gas was bubbled and driven out of a glass flask containing the analyte solvent. The flask, which was in an insulated bubbler, was maintained at $0{ }^{\circ} \mathrm{C}$ using an ice water bath to generate a constant saturated vapor pressure (SVP). The reference and carrier gases were mixed before they were sent to the gas chamber. The concentration of the analyte vapor can be approximated based on the equation below, where SVP/ATM is the ratio of the analyte saturation vapor pressure to standard atmospheric pressure, Vvoc is the MFC flow rate into the VOC flask, and Vall is the total flow rate (1000 sccm). The SVP was extracted using the Antoine coefficients of the selected analyte liquid at $273 \mathrm{~K}$.

Gas concentration $=\frac{V_{V O C}}{V_{\text {all }}} \cdot \frac{S V P}{A T M}=V_{V O C} \cdot\left(\frac{1}{V_{\text {all }}} \cdot \frac{S V P}{A T M}\right)$

The closed chamber was initially set at a humidity below $9 \% \mathrm{RH}$ and a stage temperature of $20{ }^{\circ} \mathrm{C}$, which were maintained during gas injection by using a constant moisture and heat controller connected to the main computer. The sensing signal was recorded using a Keithley 2400 S system linked to a sensor device by an electrical feedthrough. Initially, air (79\% nitrogen and $21 \%$ oxygen) was supplied to the gas chamber at $1000 \mathrm{sccm}$. When the DT-PDTT2T-TT: $\left[\mathrm{C}_{1} \mathrm{C}_{12} \mathrm{I} \mathrm{M}^{+}\right]\left[\mathrm{PF}_{6}{ }^{-}\right]$chemiresistors reached a stable baseline current, the analyte gases were injected at various concentrations. The total flow rate was fixed at $1000 \mathrm{sccm}$ by adjusting the flow from the two MFCs to avoid temperature fluctuations near the surface of the organic chemiresistors.

\section{Results and discussion}

First, we developed the desired solid-state ionic liquid that are compatible with $\pi$-CPs via the introduction of imidazolium cations containing a long alkyl chain (C12). Further modification of the developed imidazolium cations and hexafluorophosphate $\left(\mathrm{PF}_{6}^{-}\right)$anions was carried out to obtain an ionic liquid that was a solid powder at room temperature, hereafter called solid-state ionic liquid (SIL) (Fig. 1a and Supporting Information, Fig. S1-S3) ${ }^{26,27}$. The developed SIL was optically transparent and highly soluble in typical organic solvents (Supporting Information, Fig. S4). The high solubility of our SIL enabled a favorable molecular-level interaction with the $\pi$-CP used (here poly[[2,5-bis(2-octyldodecyl)-2,3,5,6-tetrahydro-3,6-

dioxopyrrolo[3,4-c]pyrrole-1,4-diyl]-alt-[[2,2 thiophene)bis-thieno(3,2-b)thiophene]-5,5'-diyl]], DP-PDPP2TTT, hereafter TT).(28) The molecular-level interactions of the TT polymer and the SIL in the blended films were confirmed via optical and vibrational spectroscopic techniques (see
Supporting Information, Fig. S5 and S6). For TOC device operation, the TT:SIL blend films are coated between two gold electrodes, as shown in Fig. 1b. When an electric field with sufficient strength to shift the Fermi level into the $\pi$ band of TT is applied between the two electrodes (the inset of Fig. 1b) ${ }^{25}$, the electrons in TT are easily released through the electrode, and injected holes are stabilized by the surrounding PF6- anions via electrostatic interactions ("on" state), thereby providing a large drain current through the channel (referred to here as "accumulation-mode operation", Fig. 1c) ${ }^{29}$. This electrochemical doping process is reversible upon inversion of the electric field.

The impact of molecular-level electrochemical doping of TT on its electrical properties was confirmed by employing a fourpoint probe method in which a current flowed through two outer probes and the voltage was measured through two inner probes $^{25}$. The $\sigma$ of TT:SIL blends system was initially evaluated at room temperature as a function of the TT:SIL mass ratio, which was increased from 1:0 to 1:10 (weight by weight, w/w) (Fig. 1d). The $\sigma$ increased dramatically from $1.07 \times 10^{-4} \mathrm{~S} / \mathrm{cm}$ to $2.70 \times 10^{-1} \mathrm{~S} / \mathrm{cm}$ as the mass ratio of the TT:SIL film increased from 1:0 to $1: 5(\mathrm{w} / \mathrm{w})$, and then the $\sigma$ decreased down to $5.1 \times$ $10^{-3} \mathrm{~S} / \mathrm{cm}$ at the blend ratio of $1: 10 \mathrm{w} / \mathrm{w}$. The maximum $\sigma$ of TT:SIL was almost 3 orders of magnitude higher than that of neat TT under the same conditions, indicating that the molecular-level electrochemical doping of the blend efficiently modulated the electrical properties without requiring gate bias in a three terminal FET configuration ${ }^{29}$. Furthermore, we found that this doping state in the TT:SIL TOCs $(L=20 \mu \mathrm{m}, W=3000$ $\mu \mathrm{m}$ ) was highly air-stable, with a high level of drain current (> $\left.10^{-8} \mathrm{~A}\right)$ at various voltages $\left(-0.1<\mathrm{V}_{\mathrm{ds}}<-20 \mathrm{~V}\right)$, whereas the neat TT or SIL TOCs exhibited an extremely low current $\left(<10^{-11} \mathrm{~A}\right)$ at $\mathrm{V}_{\mathrm{ds}}=-1 \mathrm{~V}$ and unstable behavior at relatively high voltages $\left(\mathrm{V}_{\mathrm{ds}}\right.$ $>-5 \mathrm{~V}$ ) (Fig. 1e). We anticipated that the stable and distinctive current level of TT:SIL TOCs depending on their blend ratio are attributed to a based-centered monoclinic structure of SIL and a different nanomorphology of TT:SIL film, respectively (Supporting Information, Fig. S7-S9).

We expected that the exposure of the TT:SIL TOCs to VOCS would influence the electrochemical doping process, thereby producing distinguishable electrical signals. We printed TT:SIL films with a different blend ratio of 1:1, 1:2, 1:3, 1:5, 1:7 and $1: 10(\mathrm{w} / \mathrm{w})$ over a large area $\left(60 \mathrm{~cm}^{2}\right)$ on flexible polyethylene naphthalene (PEN) substrates. Au source/drain electrodes $(L=$ $20 \mu \mathrm{m}, W=3000 \mu \mathrm{m}$ ) were finally deposited on top of the prepared substrate (Fig. 2a). Then, the VOC sensing responses of the TOCs were analyzed as a function of VOC concentration under low power consumption conditions $\left(<0.1 \mu \mathrm{W}\right.$, where $V_{\mathrm{ds}}$ $<-1 \mathrm{~V}$ and $\mathrm{Ids} \approx 1 \times 10^{-7} \mathrm{~A}$ ) by using our homemade VOC sensing system (Fig. 2b). The transient VOC sensing behavior of TOCs in response to polar (acetone, 2-propanol) and nonpolar (toluene, chlorobenzene) gases was recorded in a cycle of $60 \mathrm{sec} O N$ and OFF exposure, as shown in Fig. 2c-2f, respectively. We found that the gas response values of the TOCs were completely dependent on the polarity of the VOCs; a positive response (increased resistance) and negative recovery (decreased resistance) were obtained for cyclic exposure to acetone and 2- 
propanol (polar VOCs), while the opposite trends were observed for toluene and chlorobenzene (nonpolar VOCs) at various concentrations ranging from $3000 \mathrm{ppm}$ to $20 \mathrm{ppm}$. Interestingly, the highest sensitivity (\%) were achieved at the blend ratio of TT:SIL=1:7 ( $/ / w)$ for polar VOCs like acetone and 2-propanol, and 1:3 $(\mathrm{w} / \mathrm{w})$ for nonpolar VOCs like toluene and chlorobenzene; the optimized gas sensing characteristics upon acetone, 2-propanol, toluene and chlorobenzene exposure were shown in Fig. $2 \mathrm{~g}-2 \mathrm{j}$, respectively. In addition, it is worthwhile to note that the optimized TT:SIL TOCs could produce a reliable signal that can be distinguished from noise signals even at a level of several hundred $\mathrm{ppb}$ of acetone and toluene, respectively. Based on the further VOC sensing characteristics, the limit of detection (LOD) of TT:SIL $(1: 7 \mathrm{w} / \mathrm{w})$ and $(1: 3 \mathrm{w} / \mathrm{w})$ TOC for acetone and toluene gases was calculated to be $344 \mathrm{ppb}$ and $413 \mathrm{ppb}$, respectively, using the following equation from the International Conference on Harmonization (ICH) model:

$$
\mathrm{LOD}=3.3 \times \mathrm{SD} / \mathrm{b}
$$

Here, SD is the standard deviation of the linear regression, and $\mathrm{b}$ is the slope of the regression line (Supporting Information, Fig. $\mathrm{S} 10)^{30}$. Such sub-ppm-level LODs achieved by the TT:SIL TOCs at room temperature have not been reported previously and are comparable to those of commercial-level VOC sensors composed of inorganic or hybrid materials (Supporting Information, Table S1) ${ }^{31-36}$.

Radar plot analysis was performed to observe whether pattern differences were developed among various VOCs (i.e., fingerprint). We constructed the Radar plot at the same concentration of VOCs (here $500 \mathrm{ppm}$ of acetone, 2-propanol, toluene and chlorobenzene) to implement comparative visualization for pattern recognition among the VOCs (Fig. 3a3d). We found that a covered area of radar plot for acetone (dipole moment, $\mu \sim 2$ 2.91D) or 2-propanol ( $\mu \sim 1$ 1.57D) is much larger than that of toluene $(\mu \sim 0.36 \mathrm{D})$ or chlorobenzene $(\mu \sim$ 1.55D). Furthermore, we found the dependence of a boiling point on VOC selectivity. For example, the TT:SIL TOC shows a slightly larger covered area upon acetone exposure (boiling point, B. P. $\sim 56^{\circ} \mathrm{C}$ ) as compared to that of 2-propanol exposure (B. P. $\sim 82.5^{\circ} \mathrm{C}$ ) regardless of the blend ratio. Similar trends were found in toluene (B. P. $\sim 110.6{ }^{\circ} \mathrm{C}$ ) and chlorobenzene exposure (B. P. $\sim 132^{\circ} \mathrm{C}$ ). Therefore, we concluded that the both polarity and B. P. of VOCs can markedly affect a distinctive intermolecular interaction on the TT:SIL film surface, changing the covered area and shape of corresponding Radar plot to improve their selectivity and sensitivity of the TT:SIL TOCs.

The changes in the electrical properties of the TT:SIL TOCs upon the VOC exposure can be associated with the strong ionic crystal property of the SIL. To clarify the relationship between the molecular packing structure of the SIL and the VOC sensing characteristics of the TT:SIL TOCS, we selected the best device condition, TT:SIL=1:7 and 1:3 $(\mathrm{w} / \mathrm{w})$ blend ratio for detecting acetone and toluene, respectively, and conducted in situ GIWAXS measurements on the corresponding TT:SIL film. Before and after the $2000 \mathrm{ppm}$ of acetone exposure in $\mathrm{N}_{2}$ base gas for $3 \mathrm{~min}$, we obtained a two-dimensional (2-D) GIWAXS pattern, indicating significant reduction of all diffraction peak of
SIL, in particular, (001) plane of diffraction peak; the (001) plane could be assigned to a lamellar stacking of SIL along with out-ofplane direction (Fig. $4 a$ and $4 b$ ). The out-of-plane 1-D profiles extracted from the corresponding 2-D GIWAXS also confirmed a large quenching of diffraction peak of (001) plane at $q_{z}\left(\AA^{-1}\right)=$ $0.274 \AA^{-1}\left(d_{(001)}=22.9 \AA\right)$. This result suggests the possibility of less molecular orientation of the SIL by intermolecular interactions between the polar VOC and SIL, consequently leading to decreased electrochemical doping of the TT polymer. Notably, however, before and after the toluene exposure at the same condition, a diffraction peak of (001) plane at $q_{z}\left(\AA^{-1}\right)=$ $\left.0.263 \AA^{-1}\left(d_{(001)}\right)=23.8 \AA\right)$ with a broadened peak width was observed without quenching the overall peak intensity (Fig. 4d$4 \mathrm{f})$. In addition, the inset figure shows the increase and shift in the second-order diffraction peak of (002) plane, clearly indicating that the nonpolar VOC does not influence the ionic interactions of the SIL but rather intercalates into the SIL to make additional space for the ionic movement of $\mathrm{PF}_{6}{ }^{-}$ions, thus allowing greater electrochemical doping of the TT polymer. Therefore, we attribute that the electrochemical doping of the TT:SIL TOCs can be sensitively and selectively affected by the surrounding molecular-level environment, such as the intermolecular interaction/intercalation between the SIL and VOCs, which provides analytically useful electrical signals.

\section{Conclusions}

In conclusion, we report that $\pi$-CPs electrochemically doped with SIL can be used to discriminate surrounding molecularlevel interactions/intercalations between organic sensing materials and VOCs. Due to the long alkyl chains in the ionic liquid, we successfully demonstrate that the SIL can provide a favorable surface energy relative to that of $\pi$-CPs and thus can form a homogeneous blended system with $\pi$-CPs, resulting in efficient molecular-level electrochemical doping in the twoterminal device configuration. Since the electrochemical doping of $\pi$-CPs by SIL significantly improves their electrical conductivity $\left(\sim 10^{-1} \mathrm{~S} / \mathrm{cm}\right)$ and enhance the intermolecular interaction with VOCs at the film surface, these devices feature fine discriminatory abilities for the molecular interaction/intercalation kinetics of sub-ppm-level VOCs at room temperature and ultralow power consumption $1<0.1$ $\mu \mathrm{W})$. These devices also fulfill specific requirements for desirable organic chemiresistors, such as high selectivity, sensitivity, speed, and stability. The proposed sensing technology based on high-performance $\pi$-CPs:SIL two-terminal device can considerably extend the range of future humanmachine interface technologies.

\section{Conflicts of interest}

There are no conflicts to declare.

\section{Acknowledgements}


S. K. and Y. P. contributed equally to this work. This research was supported by the Global Research Laboratory Program of the National Research Foundation (NRF) funded by the Ministry of Science, ICT \& Future Planning (NRF-2017K1A1A2013153); the Young Researchers Program of the NRF funded by the Ministry of Science, ICT \& Future Planning (NRF2018R1C1B6006177); and GIST Research Institute(GRI), RISE grant funded by the GIST in 2020. G. Y. Jung was supported by the Pioneer Research Center Program (NRF2016M3C1A3908893) of the National Research Foundation of Korea (NRF), which is funded by the Ministry of Science and ICT \& Future Planning. We thank the Heeger Center for Advanced Materials (HCAM) and the GIST-ICL International Collaboration R\&D center at Gwangju Institute of Science and Technology (GIST) of Korea for assistance with device fabrication and characterization. We acknowledge the UK EPSRC for studentships under the Centre for Doctoral Training (CDT) in Plastic Electronics (EP/G037515/1).

\section{Author contributions}

S. K., Y. P., G. Y. J. and K. L. designed the concept and the required experiments. S. K. and $Y$. P. fabricated the sensors, conducted the gas sensing experiments and analyzed the obtained data. B. K., S. J. and H. K. conducted the material synthesis and characterization of the ionic liquid crystals. Y. J. and B. K. performed the TEM measurements. S. K. and J. K. performed the GIWAXS measurements. J. M. and B. P. conducted the FT-IR measurements and prepared the figures. S. L., K. S. and J. K. conducted the optical and energetic measurements. S. K., Y. P., J. K., G. Y. J., and K. L. interpreted the data and wrote the manuscript. All authors discussed the results and commented on the manuscript.

\section{Notes and references}

1 M. Phillips, Anal. Biochem. 1997, 247, 272-278.

2 M. Phillips, K. Gleeson, J. M. B.Hughes, J. R. Greenberg, N. Cataneo, L. Baker, W. P. McVay, The Lancet 1999, 353, 19301933.

3 T. A. T. G. van Kempen, W. J. Powers, A. L. Sutton, J. Anim. Sci. 2002, 80, 1524-1527.

4 G. Peng, U. Tisch, O. Adams, M. Hakim, N. Shehada, Y. Y. Broza, S. Billan, R. Abdah-Bortnyak, A. Kuten, H. Haick, Nat. Nanotech. 2009, 4, 669-673.

5 M. Righettoni, A. Tricoli, S. E. Pratsinis, Anal. Chem. 2010, 82, 3581-3587.

6 T. Xiao, X. Wang, Z. Zhao, L. Li, L. Zhang, H. Yao, J. Wang, Z. Li, Sens. Actuators, B. 2014, 199, 210-219.

7 M. Mori, Y. Itagaki, J. Iseda, Y. Sadaoka, T. Ueda, H. Mitsuhashi, Sens. Actuators, B. 2014, 202, 873-877.

8 A. Berna, Sensors, 2010, 10, 3882-3910.

9 G. Konvalina, H. Haick, ACS Appl. Mater. Interfaces 2012, 4, 317-325.

10 J. Kim, H. Yoo, H. Choi, H. Jung, Nano Lett. 2014, 14, 59415947.

11 J. Janata, M. Josowicz, Nat. Mater. 2003, 2, 19-24.

12 H. Bai, G. Shi, Sensors, 2007, 7, 267-307.

13 B. Li, G. Sauve, M. C. Lovu, M. Jeffries-El, R. Zhang, J. Cooper, S. Santhanam, L. Schultz, J. C. Revelli, A. G. Kusne, T.
Kowalewski, J. L. Snyder, L. E. Weiss, G. K. Fedder, R. D. McCullough, D. N. Lambeth, Nano Lett. 2006, 6, 1598-1602.

14 G. Ryu, K. H. Park, W. Park, Y. Kim, Y.-Y Noh, Org. Electron. 2015, 23, 76-81.

15 A. Lv, Y. Pan, L. Chi, Sensors, 2017, 17, 213.

16 D. Khim, G.-S. Ryu, W.-T. Park, H. Kim, M. Lee, Y.-Y. Noh, Adv. Mater. 2016, 28, 2752-2759.

17 P. Bergveld, IEEE Trans. on Biomed. Eng. 1970, 1, 70-71.

18 H. S. White, G. P. Kittlesen, M. S. Wrighton, J. Am. Chem. Soc. 1984, 106, 5375-5377.

19 D. Mecerreyes, Prog. in Polym. Sci. 2011, 36, 1629-1648.

20 A. S. Dhoot, J. D. Yuen, M. Heeney, L. McCulloch, D. Moses, A. J. Heeger, Natl. Acad. Sci. 2006, 103, 11834-11837.

21 M. J. Panzer, C. D. Frisbie, Adv. Funct. Mater. 2006, 16, 10511056.

22 M. J. Panzer, C. D. Frisbie, Adv. Mater, 2008, 20, 3177-3180.

23 J. Lee, L. G. Kaake, J. H. Cho, X.-Y. Zhu, T. P. Lodge, C. D. Frisbie, J. Phys. Chem. C 2009, 113, 8972-8981.

24 J.-H. Choi, W. Xie, Y. Gu, C. D. Frisbie, T. P. Lodge, ACS Appl. Mater. Interfaces, 2015, 7, 7294-7302.

25 J. D. Yuen, A. S. Dhoot, E. B. Namdas, N. E. Coates, M. Heeney, L. McCulloch, D. Moses, A. J. Heeger, J. Am. Chem. Soc. 2007, 129, 14367-14371.

26 K. Binnemans, Chem. Rev. 2005, 105, 4148-4204.

27 P. Wasserscheid, T. Welton, Ionic Liquid in Synthesis. WILEYVCH Verlag GmbH \& 399 Co. KGaA, Weinheim, Germany 2008, Chapter 2, 7-53.

28 W. Li, K. H. Hendriks, W. S. C. Roelofs, Y. Kim, M. M. Wienk, R. A. J. Janssen, Adv. Mater. 2013, 25, 3182-3186.

29 J. Rivnay, S. Inal, A. Salleo, R. M. Owens, M. Berggren, G. G. Malliaras, Nat. Rev. Mater. 2018, 3, 17086.

30 S. Chandran, R. S. P. Singh, Pharmazie, 2007, 62, 4-14.

31 S.-J. Kim, S.-J Choi, J.-S. Jang, H.-J. Cho, W.-T. Koo, H. L. Tuller, I.-D. Kim, Adv. Mater. 2017, 29, 1700737.

32 L. Wei, L. Xu, K. Sheng, X. Zhou, B. Dong, G. Lu, H. Song, NPG Asia Mater. 2018, 10, 293-308.

33 S. A. Hakim, Y. Liu, G. S. Zakharovab, W. Chen, RSC Adv. 2015, 5, 23489.

34 W.-T. Koo, S.-J. Choi, S.-J. Kim, J.-S. Jang, H. L. Tuller, I.-D. Kim, J. Am. Chem. Soc. 2016, 138, 13431-13437.

35 Y. Seekaew, A. Wisitsoraat, D. Phokharatkul, C. Wongchoosuk, Sens. Actuators, B. 2019, 279, 69-78.

36 A. N. Mallya, R. Kottokkaran, P. C. Ramamurthy, Sens. Actuators, B. 2014, 201, 308-320. 
(a)

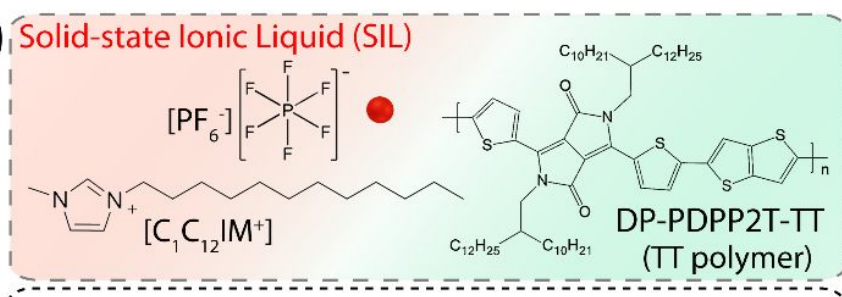

(c)

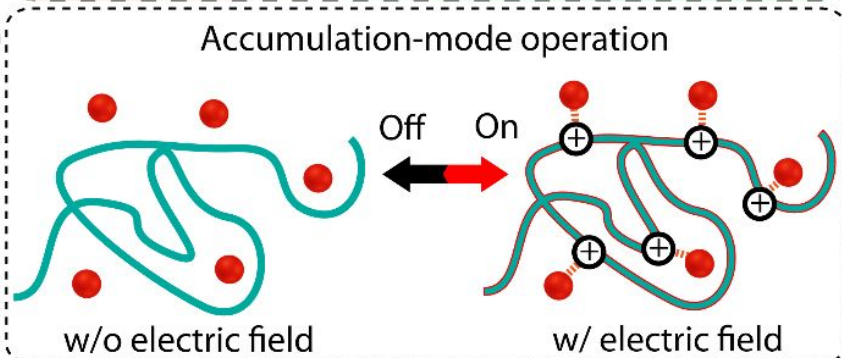

(b)

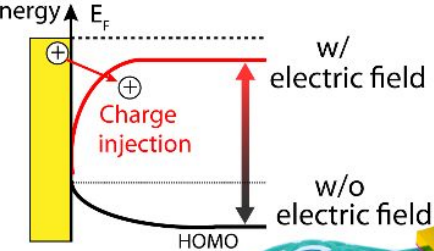

Two-terminal organic chemiresistor

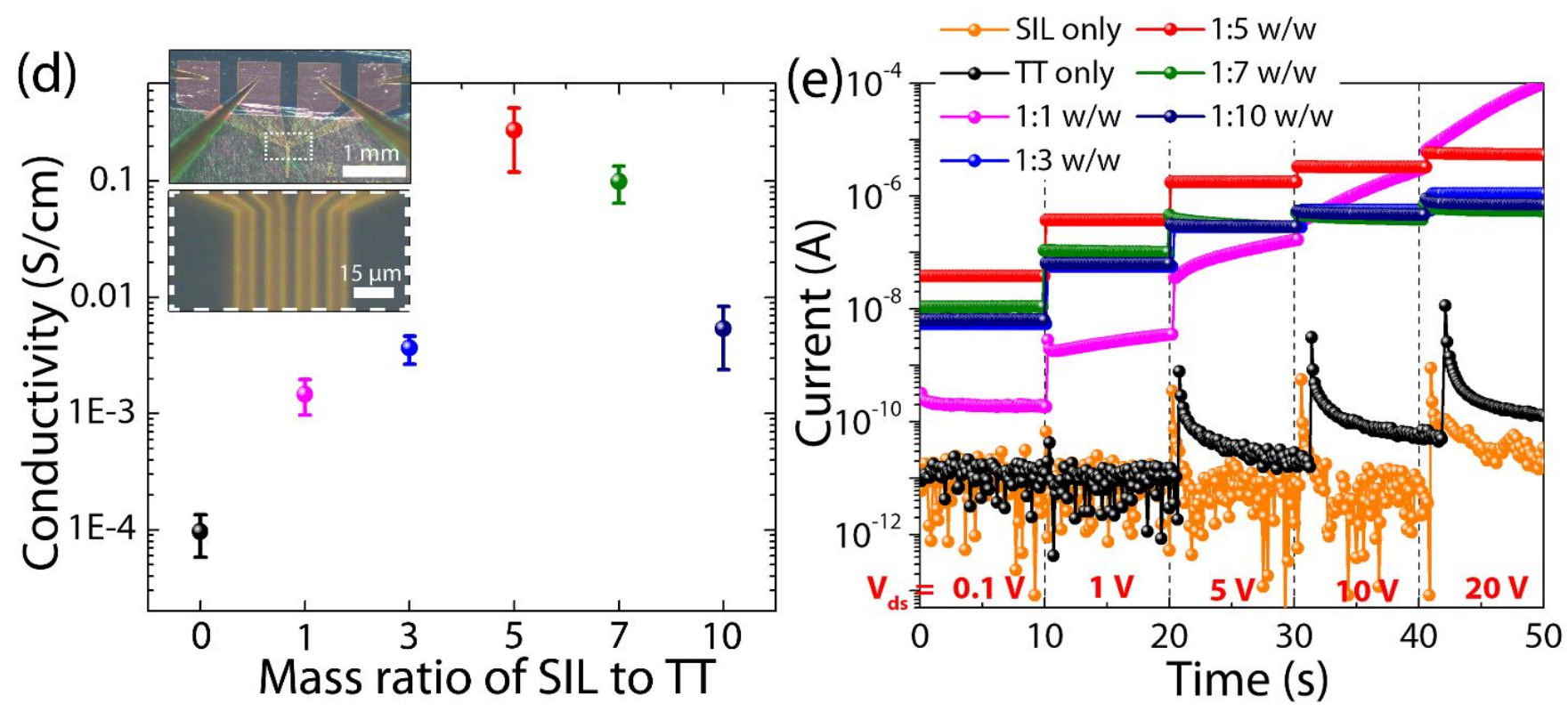

Fig. 1. (a) Chemical structures of DP-PDPP2T-TT (TT polymer) and $\left[C_{1} C_{12} I^{+}{ }^{+}\right]\left[P F_{6}{ }^{-}\right]$(SIL). The red dots represent PF6- anions. (b) Schematic illustration of the TOC consisting of the TT:SIL blend film that bridges the gap between the source (S) and drain (D) electrodes. The inset figure shows the energy level diagram exhibiting the change in the Fermi level close to the $\pi$ band of TT under an electric field. (c) Accumulation-mode operation of the TT:SIL TOCs: i) At zero source/drain voltage, few hole charges move along the channel; this is the "off state". ii) When a sufficient source/drain voltage is applied, a number of hole charges are generated by the compensating $\mathrm{PF}_{6}{ }^{-}$anions, and a large drain current flows through the channel; this is the "on state" (d) Comparison of the electrical conductivity of the neat TT and TT:SIL films prepared with different blend ratios. The inset shows the bar-shaped four-point probe configuration for the resistivity measurement of the thin films. (e) Comparison of the electrical stability of the neat TT and TT:SIL TOCs $(L=20 \mu \mathrm{m}, W=3000 \mu \mathrm{m})$ at various Vds values ranging from $-0.1 \mathrm{~V}$ to $-20 \mathrm{~V}$. 
(a)

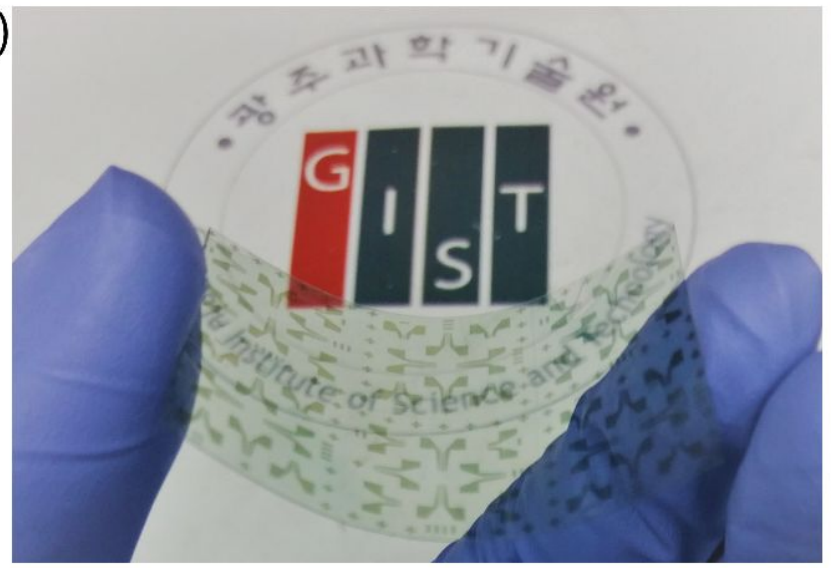

(c)
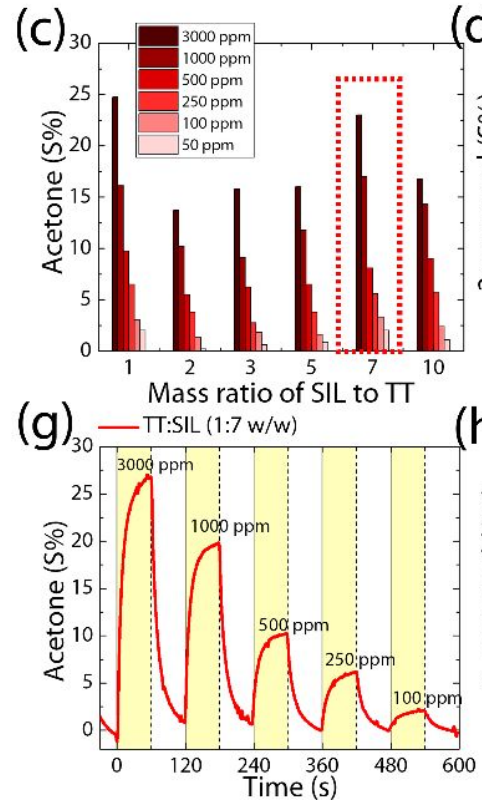

$(d)$

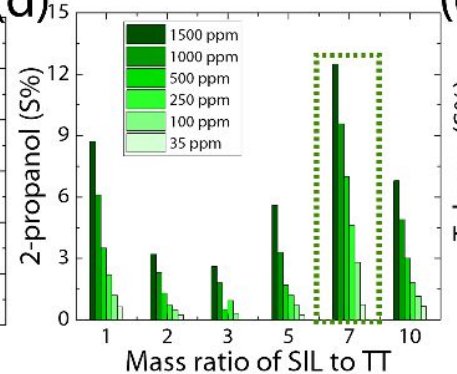
$(h)_{15}-\pi: S L L(1: 7 \mathrm{w} / \mathrm{w})$

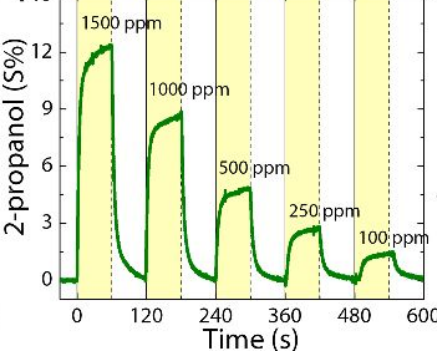

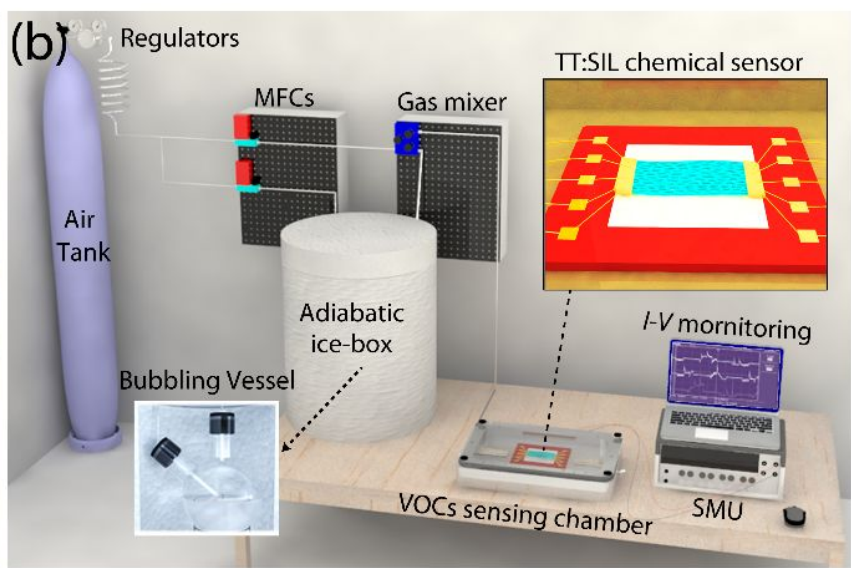

(e)
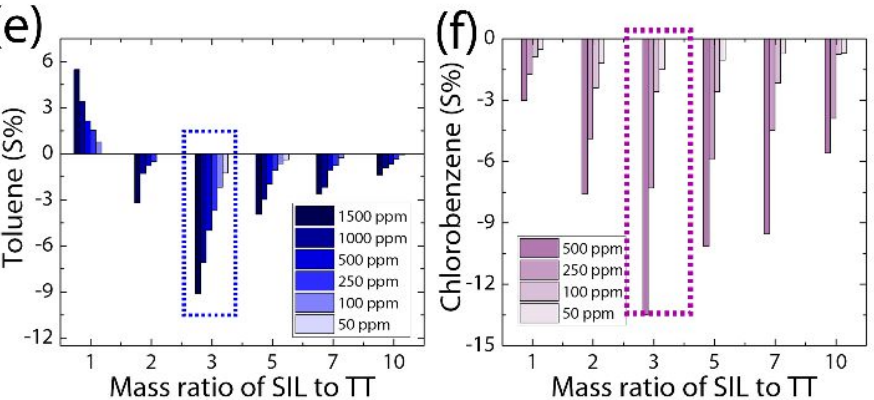
(i)
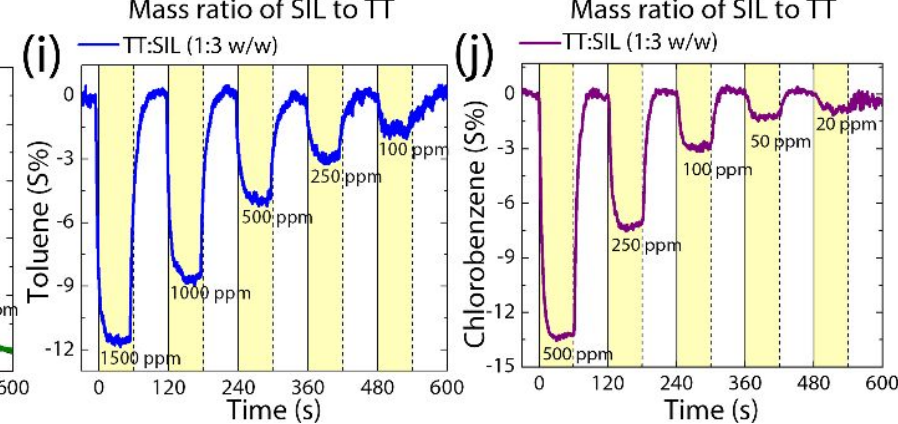

Fig. 2. (a) Photograph of printed TT:SIL TOCs on a flexible PET substrate (substrate dimensions: $10 \mathrm{~cm} \times 6 \mathrm{~cm}, L=20 \mu \mathrm{m}, W=3000 \mu \mathrm{m}$ ). (b) Illustration of the microvacuum probe station equipped with a VOC (gas) flow control system. The resultant VOC-sensing capabilities of the TT:SIL TOCs as function of TT:SIL blend ratio for (c) acetone, (d) 2-propanol, (e) toluene and (f) chlorobenzene exposure. Dot box indicate the maximum sensitivity of the TT:SIL TOCs at specific blend ratios, and the corresponding electrical response upon (g) acetone, (h) 2-propanol, (i) toluene and (j) chlorobenzene exposure. The light-yellow regions with green bars indicate the periods of exposure to the VOC. All measurements were performed at room temperature and $\mathrm{Vds}<-1 \mathrm{~V}$. To evaluate the VOC-sensing capability, we defined a gas response as sensitivity $(\%)=\left(R_{v o c}-R_{0}\right) / R_{0} \times 100$, where Rvoc is the maximum resistance of the sensor exposed to the VOC and R0 is the baseline resistance of the sensor in the absence of VOCs. 
(a)

- Acetone<smiles>CC(C)=O</smiles>

*Dipole moment : $\mu \sim 2.91 D$

**Boiling point :

$T \sim 56^{\circ} \mathrm{C}$

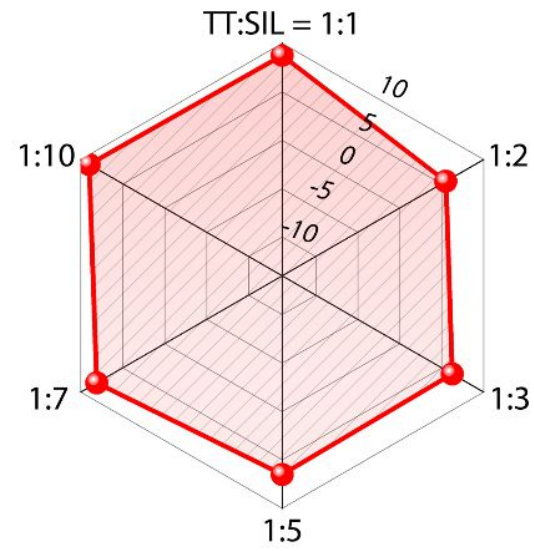

(c) --Toluene<smiles>Cc1ccccc1</smiles>

*Dipole moment : $\mu \sim 0.36 D$

**Boiling point : $T \sim 110.6^{\circ} \mathrm{C}$

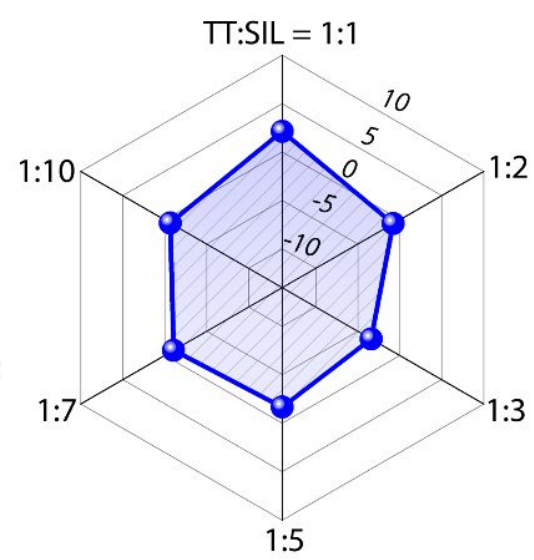

(b) -2-Propanol

$\Pi: S I L=1: 1$<smiles>CC(C)O</smiles>

*Dipole moment : $\mu \sim 1.57 D$

**Boiling point : $T \sim 82.5^{\circ} \mathrm{C}$

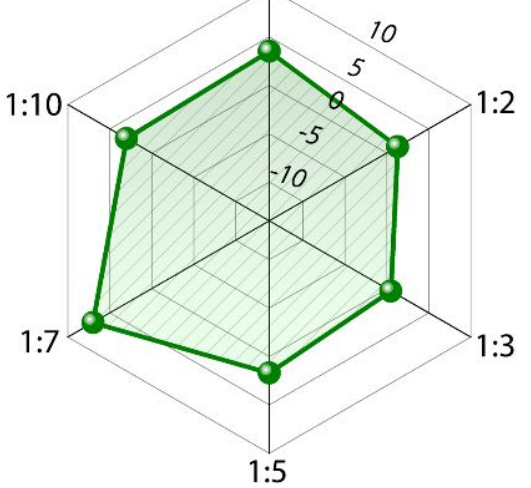

(d) - Chlorobenzene<smiles>Clc1ccccc1</smiles>

*Dipole moment : $\mu \sim 1.55 D$

**Boiling point : $T \sim 132^{\circ} \mathrm{C}$

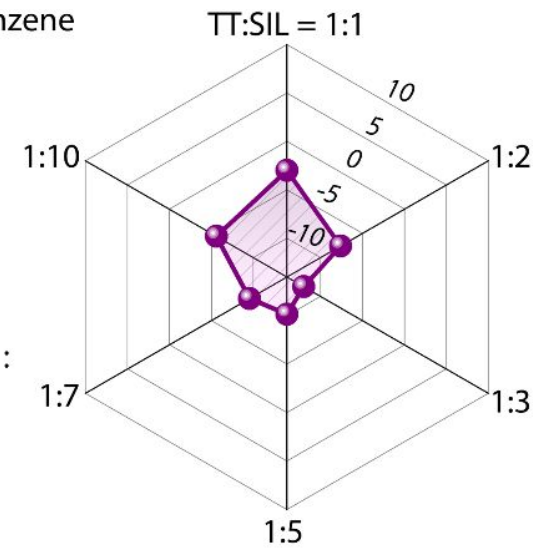

Fig. 3. Radar plot showing maximum electrical response of TT:SIL TOCs at each blend ratio for $500 \mathrm{ppm}$ of (a) acetone, (b) 2-propanol, (c) toluene and (d) chlorobenzene exposure. The relationship among radar-plot area, dipole moment and boiling point of each VOC is considered to clarify their similarities and differences. 

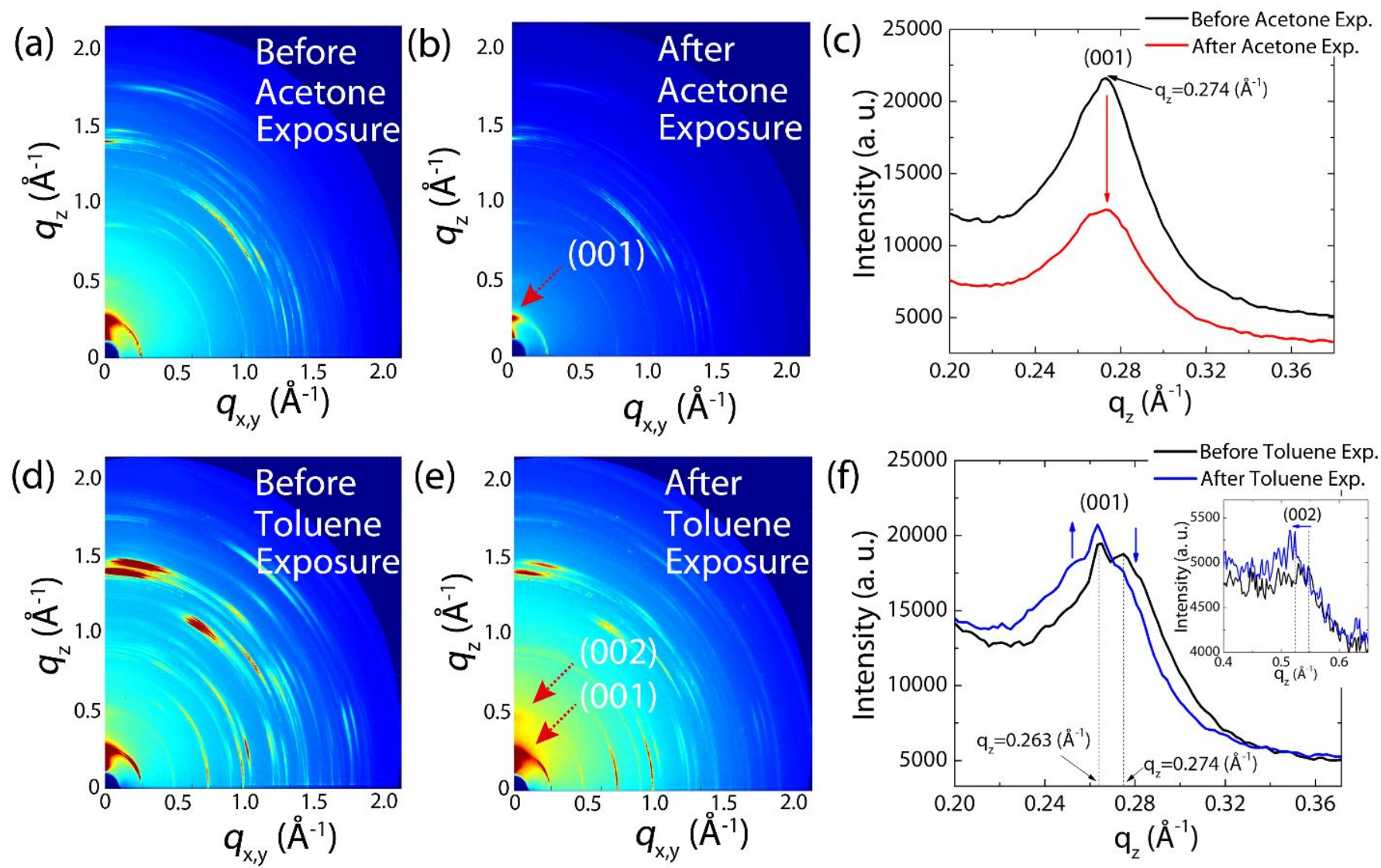

Fig. 4. (a), (b) In-situ 2-D GIWAXS patters of TT:SIL (1:7 w/w) film before and after $2000 \mathrm{ppm}$ of acetone in $\mathrm{N}_{2}$ base gas for $3 \mathrm{~min}$, respectively. (c) Changes in the 1-D GIWAXS profile of TT:SIL TOCs after acetone. Red arrow indicate the clear change of diffraction peak of (001) plane of SIL after the solvent exposure. (d), (e) In-situ 2-D GIWAXS patters of TT:SIL (1:3 w/w) film before and after 2000 ppm of toluene in $\mathrm{N}_{2}$ base gas for $3 \mathrm{~min}$, respectively. (f) Changes in the 1-D GIWAXS profile of TT:SIL TOCs after toluene. The inset figure shows the shift in the secondorder peak toward a smaller $q_{z}$, indicating the intercalation of toluene into the SIL. 


\section{Graphical abstract}

We demonstrate that a blend of $\pi$-CPs and a solid-state ionic liquid provides an enlarged interfacial area at the molecular scale, thereby enabling two-terminal organic chemiresistors (TOCs) with fine discriminatory abilities for sub-ppm-level VOCs at room temperature.

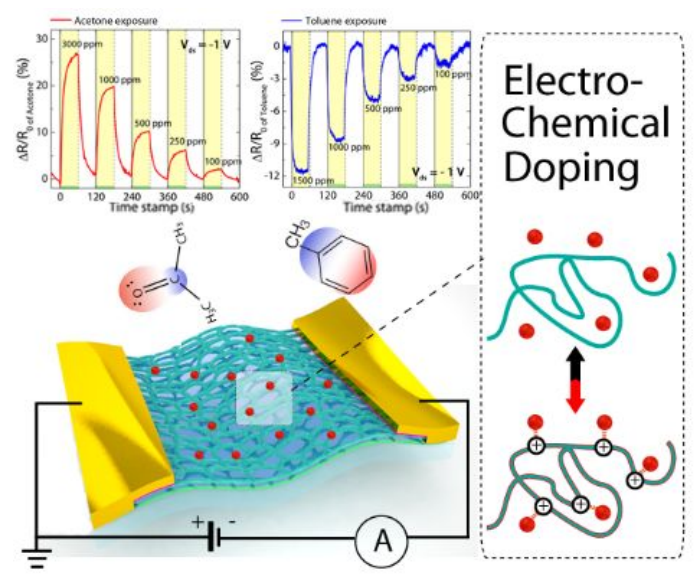

Two-terminal organic chemiresistor 


\section{Supporting Information}

\section{Molecular-level electrochemical doping for fine discrimination of volatile organic compounds in organic chemiresistors}

Sooncheol Kwon ${ }^{a * \dagger}$, Yusin $\mathrm{Pak}^{\mathrm{b} \dagger}$, Bongseong Kim ${ }^{\mathrm{d}}$, Byoungwook Park ${ }^{\mathrm{c}}$, Jehan Kim ${ }^{\mathrm{e}}$, Geunjin $\mathrm{Kim}^{\mathrm{d}}$, Yong-Ryun $\mathrm{Jo}^{\mathrm{c}}$, Saurav Limbu ${ }^{\mathrm{f}}$, Katherine Stewart ${ }^{\mathrm{f}}$, Hyeonghun Kim ${ }^{\mathrm{c}}$, Bong-Joong Kim ${ }^{\mathrm{c}}$, Soo-Young Jang ${ }^{\mathrm{a}}$, Hongkyu Kang ${ }^{\mathrm{a}}$, Jung-Wook Min' ${ }^{\mathrm{g}}$, Ji-Seon Kim ${ }^{\mathrm{f} *}$, Gun Young Jung ${ }^{\mathrm{c} *}$ and Kwanghee Leea ${ }^{c *}$

a Research Institute for Solar and Sustainable Energies (RISE), Gwangju Institute of Science and Technology (GIST), Gwangju 500-712, Republic of Korea. E-mail: kwansc@gist.ac.kr b Sensor System Research Center (SSRC), Korea Institute of Science and Technology (KIST), Seoul 02792, Republic of Korea.

c School of Materials Science and Engineering (SMSE), Gwangju Institute of Science and Technology (GIST), Gwangju 500-712, Republic of Korea. E-mail: klee@gist.ac.kr

d Heeger Center for Advanced Materials (HCAM), Gwangju Institute of Science and Technology (GIST), Gwangju 500-712, Republic of Korea.

e Pohang Accelerator Laboratory, Pohang University of Science and Technology, Pohang 37673, Republic of Korea.

${ }^{\mathrm{f}}$ Department of Physics and Centre for Plastic Electronics, Imperial College London, London, SW7 2AZ, United Kingdom.

g Physical Sciences and Engineering Division, King Abdullah University of Science and Technology (KAUST), Thuwal, Kingdom of Saudi Arabia

*Correspondence $\quad$ to: $\quad$ kwansc@gist.ac.kr; $\quad$ ji-seon.kim@imperial.ac.uk;

gyjung@gist.ac.kr; klee@gist.ac.kr

†. K. and Y. P. contributed equally to this work. 
Table S1. Summary of recent publications on chemiresistors based on inorganic or hybrid materials for detecting acetone and toluene and comparison with the sensing capability of the TT:SIL TOCs developed in this work.

\begin{tabular}{|c|c|c|c|c|c|c|}
\hline Materials & $\begin{array}{l}\text { Operation } \\
\text { Temp. }\left({ }^{\circ} \mathrm{C}\right)\end{array}$ & $\begin{array}{l}\text { Target } \\
\text { VOC }\end{array}$ & $\begin{array}{l}\text { LOD } \\
(\mathrm{ppm})\end{array}$ & Responsivity (\%) & $\begin{array}{l}\text { Response } \\
\text { /Recovery } \\
\text { (s) }\end{array}$ & Reference \\
\hline $\begin{array}{c}\text { PtPd-WO } \mathrm{WO}_{3} \\
\mathrm{NF} \\
\text { (Inorganic) }\end{array}$ & 300 & Acetone & 0.001 & 9750 (at $1 \mathrm{ppm})$ & $<4.2 /<204$ & 31 \\
\hline $\begin{array}{c}\mathrm{Pt} @ \operatorname{In}_{2} \mathrm{O}_{3} \\
\mathrm{NF} \\
\text { (Inorganic) }\end{array}$ & 320 & Acetone & 0.01 & 623 (at $1 \mathrm{ppm}$ ) & $11 / 13$ & 32 \\
\hline $\begin{array}{c}\mathrm{V}_{2} \mathrm{O}_{5} \\
\text { nanoneedle } \\
\text { (Inorganic) }\end{array}$ & R.T. & Acetone & 1.7 & $\begin{array}{c}137 \text { (at } 140 \\
\text { ppm) }\end{array}$ & $70 /-$ & 33 \\
\hline $\begin{array}{c}\text { Pd-@ZnO- } \\
\text { WO }_{3} \mathrm{NF} \\
\text { (Inorganic) }\end{array}$ & 350 & Toluene & $<0.1$ & 2222 (at $1 \mathrm{ppm})$ & $20 /-$ & 34 \\
\hline $\begin{array}{l}\text { Poly(DTCP } \\
\text { A-co- } \\
\text { BHTBT)- } \\
\text { carbon black } \\
\text { (Hybrid) }\end{array}$ & R.T. & Toluene & 15 & $\begin{array}{l}0.5 \text { (at } 150 \\
\text { ppm) }\end{array}$ & $35 / 84$ & 35 \\
\hline $\begin{array}{c}\mathrm{TiO}_{2^{-}} \\
\text {decorated } \\
\text { 3D } \\
\text { Graphene- } \\
\text { CNT } \\
\text { (Hybrid) }\end{array}$ & R.T. & Toluene & 50 & 4 (at $100 \mathrm{ppm})$ & $6 / 7$ & 36 \\
\hline \multirow{2}{*}{$\begin{array}{l}\text { TT:SIL } \\
\text { (Organic) }\end{array}$} & \multirow[t]{2}{*}{ R.T. } & Acetone & 0.34 & 2.1 (at $20 \mathrm{ppm})$ & $180 / 180$ & \multirow[t]{2}{*}{ This work } \\
\hline & & Toluene & 0.41 & 1.7 (at $20 \mathrm{ppm})$ & $180 / 180$ & \\
\hline
\end{tabular}




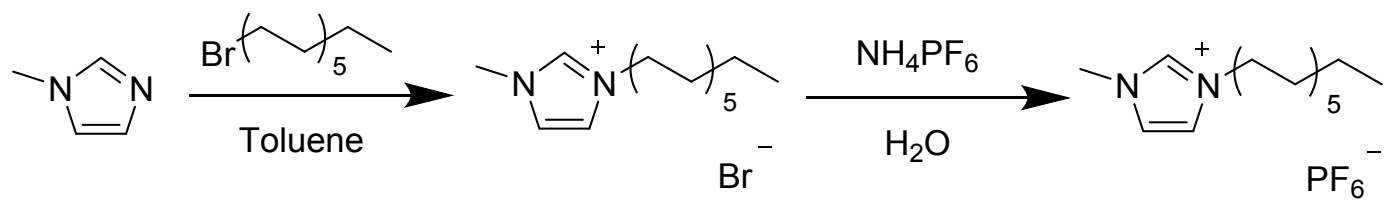

\section{$\mathrm{C}_{1} \mathrm{C}_{12} \mathrm{IMBr}$}

$\mathrm{C}_{1} \mathrm{C}_{12} \mathrm{IMPF}_{6}$

Fig. S1. Synthetic scheme for $\left[\mathrm{C}_{1} \mathrm{C}_{12} \mathrm{IM}\right]^{+}[\mathrm{Br}]^{-}$and $\left[\mathrm{C}_{1} \mathrm{C}_{12} \mathrm{IM}\right]^{+}[\mathrm{PF} 6]^{-}$.

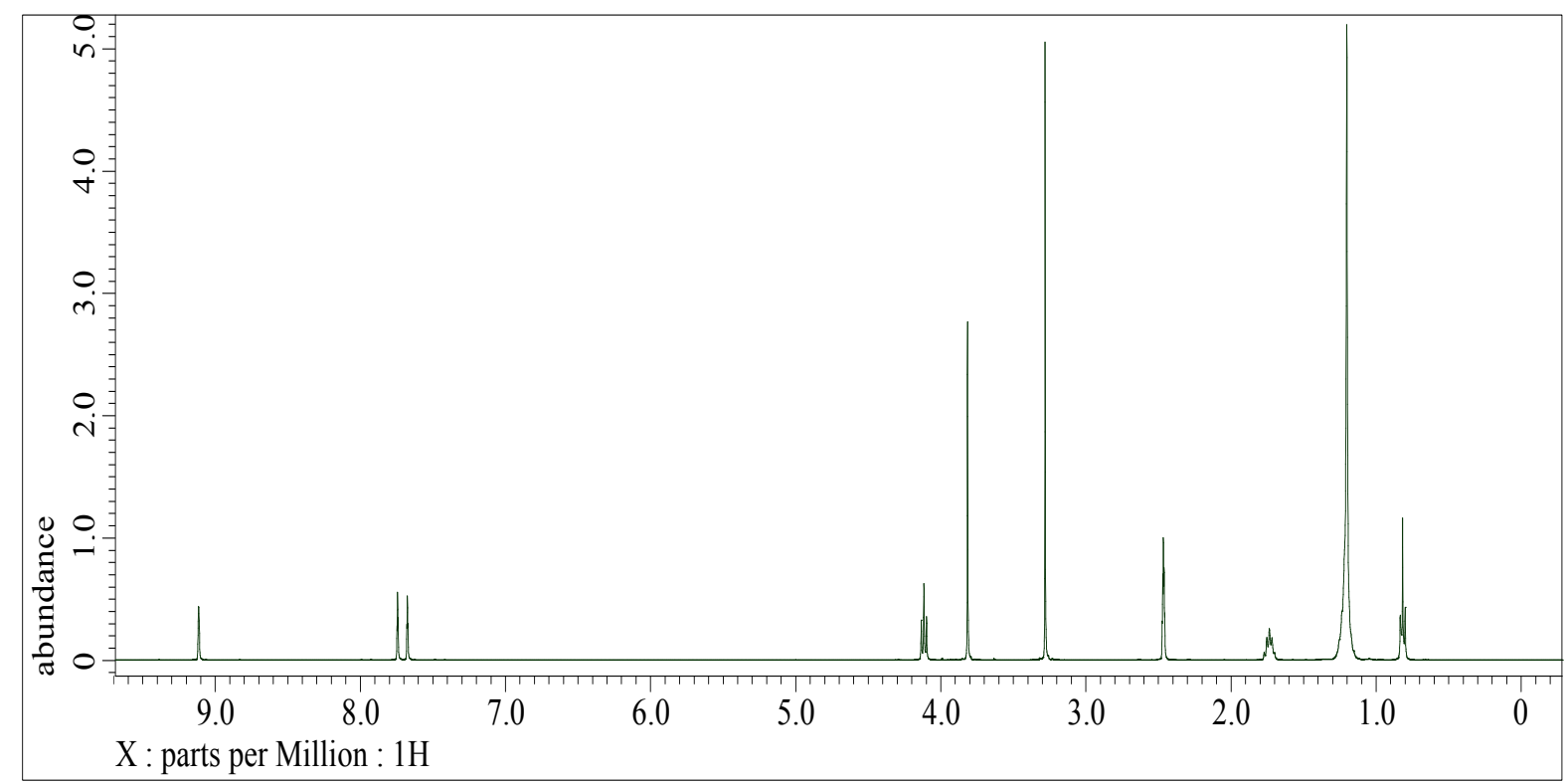

Fig. S2. Nuclear magnetic resonance (NMR) data of $\left[\mathrm{C}_{1} \mathrm{C}_{12} \mathrm{IM}\right]^{+}[\mathrm{Br}]^{-}$.

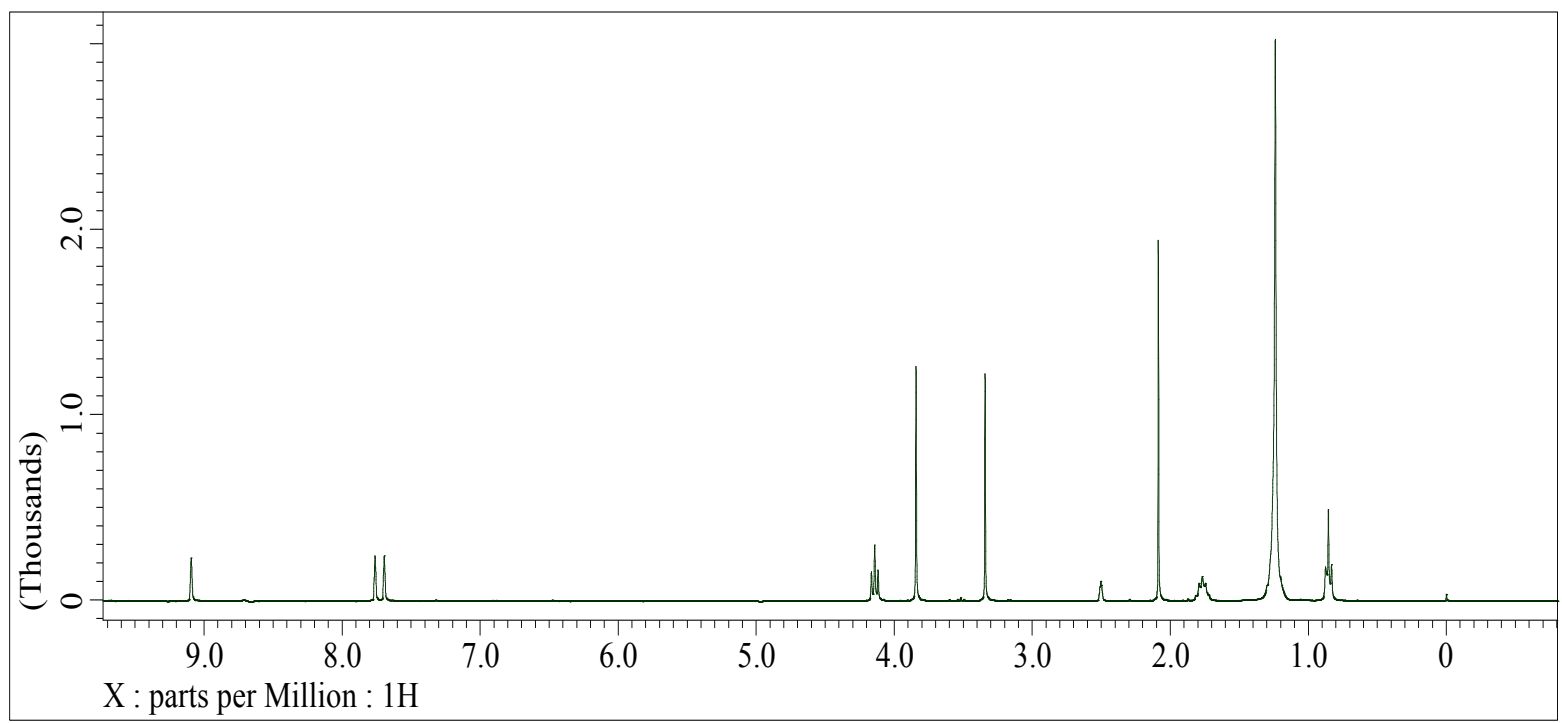

Fig. S3. NMR data of $\left[\mathrm{C}_{1} \mathrm{C}_{12} \mathrm{IM}\right]^{+}[\mathrm{PF} 6]^{-}$. 
(a)

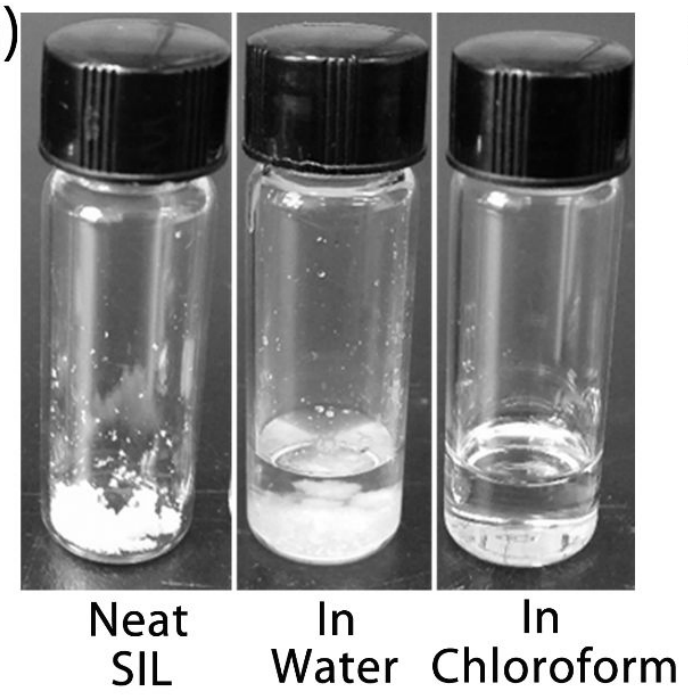

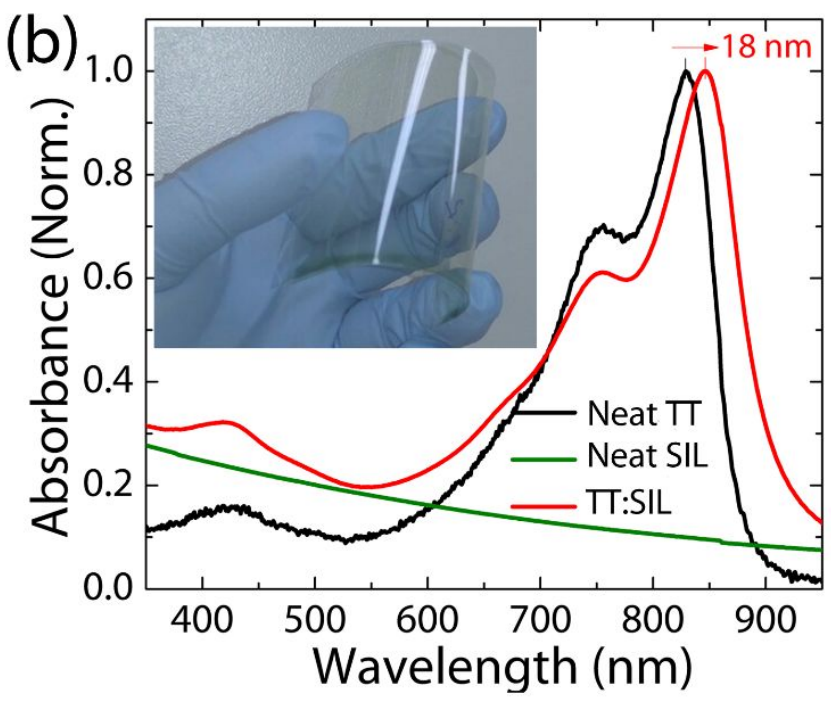

Fig. S4. (a) Comparison of the solubilities of the SIL in water (polar solvent) and chloroform (nonpolar solvent). (b) Normalized absorption spectra of as-cast neat TT, neat SIL and TT:SIL blend $(1: 5 \mathrm{w} / \mathrm{w})$ films. The inset is a photograph of a TT:SIL film on a flexible PEN substrate.

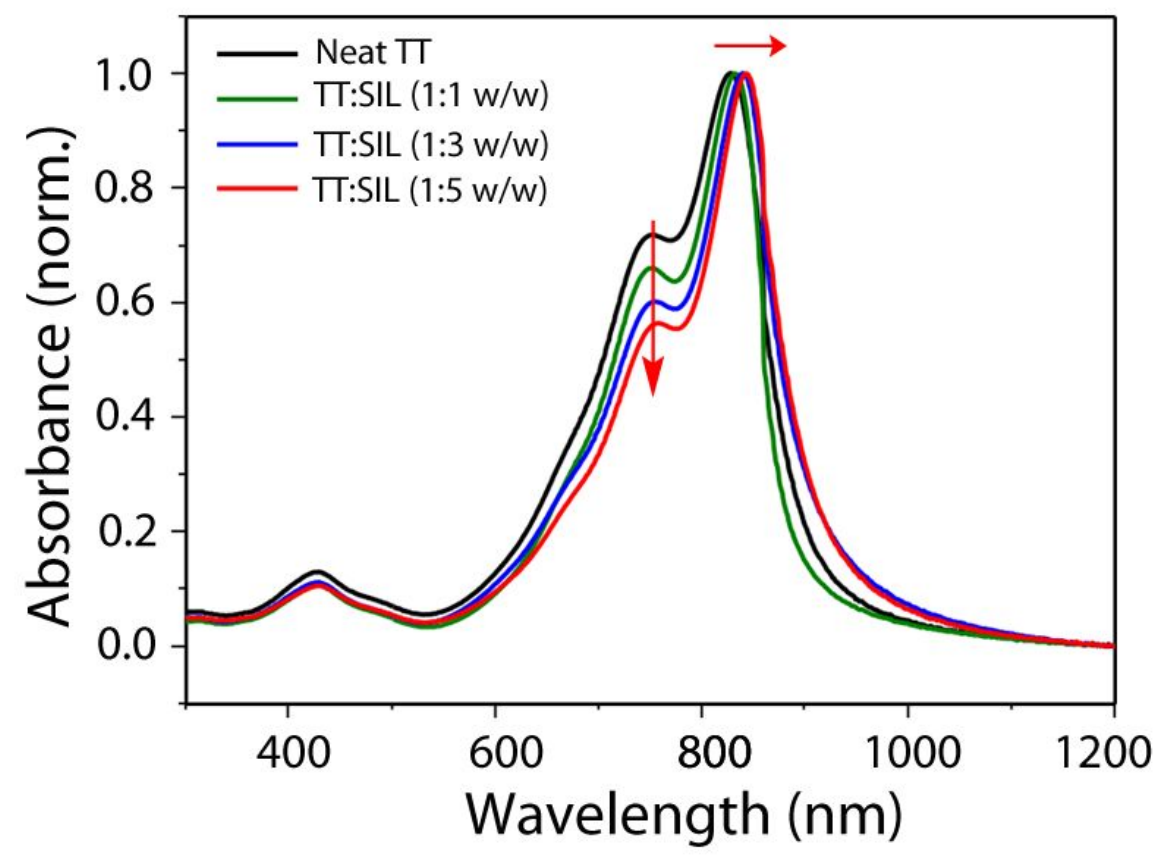

Figure S5. The optical absorption spectra of neat TT and TT:SIL $(1: 1,1: 3$ and 1:5 w/w) thin films were obtained using a UV-Vis spectrometer. The neat TT polymer exhibited typical features of a vibronically structured 0-0 transition, with an onset at $920 \mathrm{~nm}$, whereas the TT:SIL blend films exhibited absorption spectra that were similar to that of the pristine TT polymer, except for the gradual redshift (up to $\sim 18 \mathrm{~nm}$ ) in the maximum absorption peak of the blended films at $830 \mathrm{~nm}$ as the blend ratio increased. In particular, the increase in the relative ratio of the 0-0:0-1 transition of the TT:SIL film vs. the neat TT polymer film implies that the SIL enhances the intermolecular interactions of the TT polymer chains. 

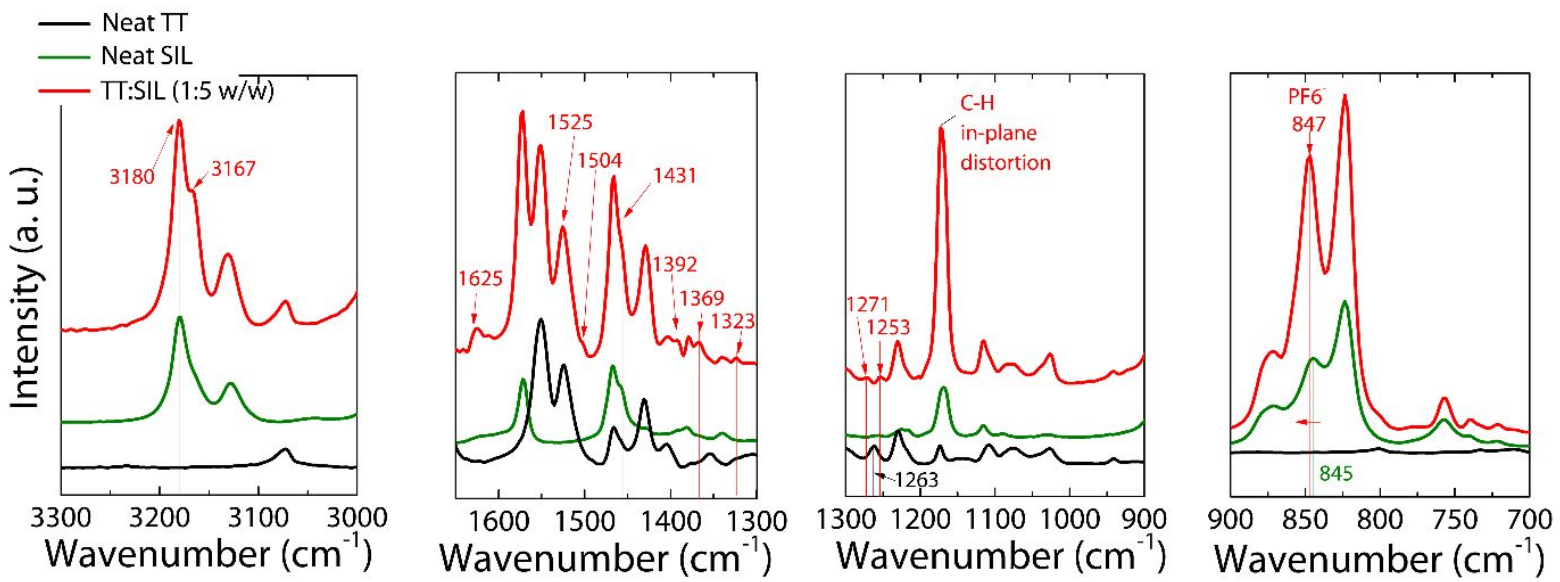

Fig. S6. The two major peaks between 3100 and $3200 \mathrm{~cm}^{-1}$ were assigned to the aromatic $\mathrm{C}-\mathrm{H}$ stretching vibrations in the imidazolium cation, while the peaks between 800 and $900 \mathrm{~cm}^{-1}$ originated from the $\left[\mathrm{PF}_{6}\right]^{-}$anion of the SIL. When the SIL is mixed with the TT polymer, the original peaks from the cations and anions of the SIL become sharper, and the peaks at 1572 $\mathrm{cm}^{-1}$ and $845 \mathrm{~cm}^{-1}$, which represent the $\mathrm{C}=\mathrm{N}^{+}$vibration mode of the imidazolium cation and the FP-F asymmetric stretching mode of the $\left[\mathrm{PF}_{6}\right]^{-}$anion, respectively, are blueshifted. This result indicates that the ionic interactions between the cations and anions of the SIL became weaker after blending with TT. In addition, compared with those of the other SIL peaks, the intensities of the peaks at $3167 \mathrm{~cm}^{-1}$ and $847 \mathrm{~cm}^{-1}$ increased after mixing with the TT polymer, which suggests that a change in the molecular interactions between the ions of the SIL occurs upon the addition of the TT polymer. Several new peaks (e.g., peaks at 1625, 1369, 1323, 1271, and $1253 \mathrm{~cm}^{-1}$ ) appeared in the spectra of the TT:SIL blend, and the peaks at 1354 and $1263 \mathrm{~cm}^{-1}$ disappeared from the spectrum. In particular, the peak at $1263 \mathrm{~cm}^{-1}$, which is attributed to the aromatic amine group of the DPP units in the TT polymer, could be split into two new peaks at $1271 \mathrm{~cm}^{-1}$ and $1253 \mathrm{~cm}^{-1}$ due to perturbation by neighboring molecules, which, in this case, were the ions of the SIL. This result is in accordance with the strong intermolecular interactions indicated by the change in the absorption spectra after the addition of the SIL to the TT polymer. 


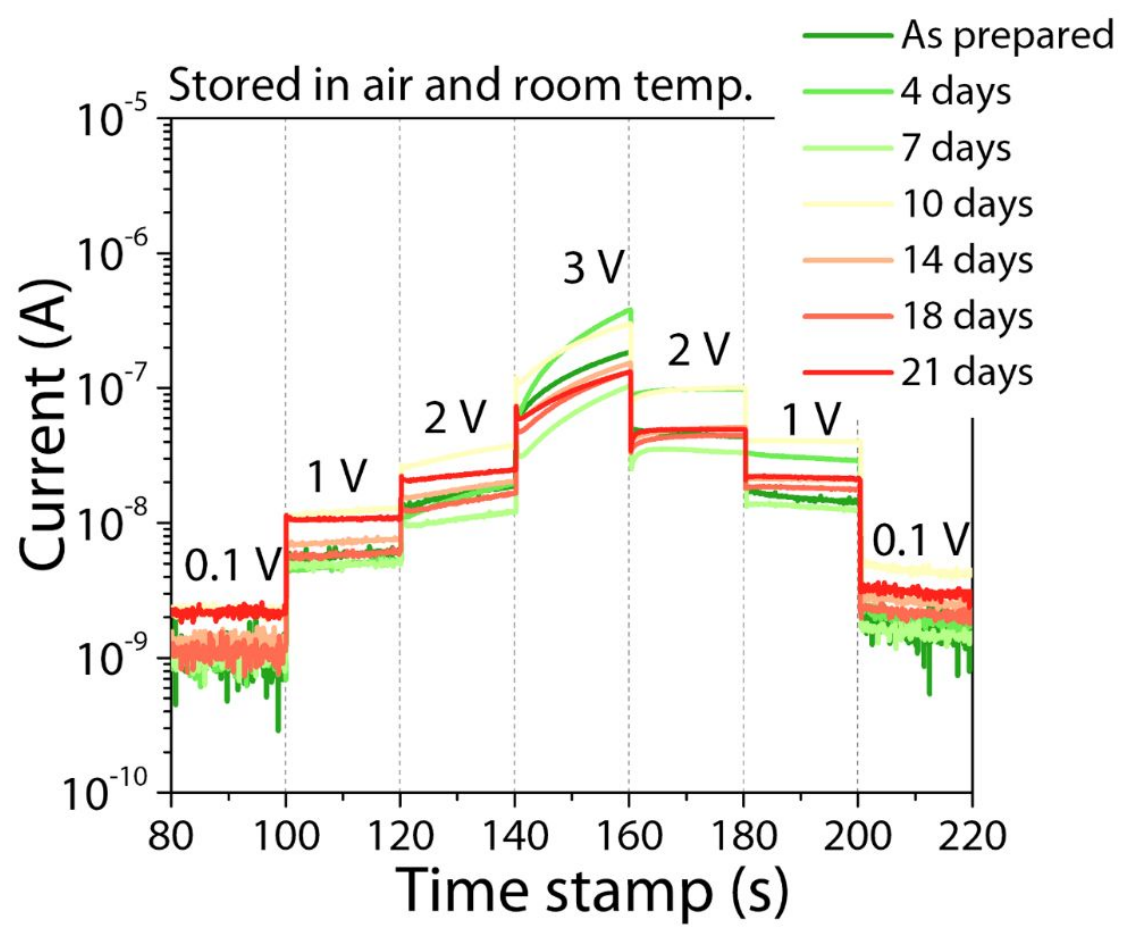

Fig. S7. Stability test for TT:SIL $(1: 5 \mathrm{w} / \mathrm{w})$ TOCs $(L=20 \mu \mathrm{m}, W=3000 \mu \mathrm{m})$ that are stored in air and room temperature conditions for 3 weeks ( 21 days); the $\mathrm{V}_{\mathrm{ds}}$ values range from $0.1 \mathrm{~V}$ to $3 \mathrm{~V}$.
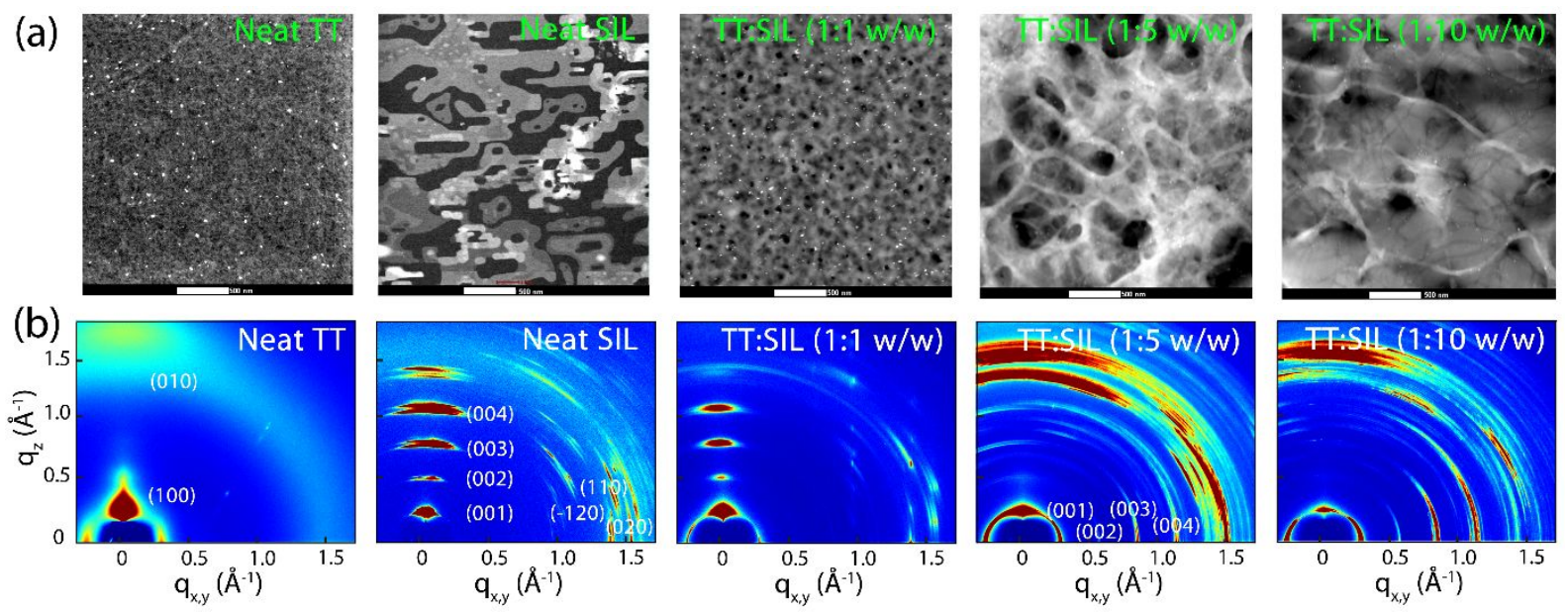

Fig. S8. (a) HAADF-STEM images of the neat TT, neat SIL and TT:SIL films with different ratios (i.e., TT:SIL $=1: 1,1: 5$, and 1:10 weight/weight). The scale bar is $500 \mathrm{~nm}$. The formation of fibrous structures in the TT:SIL film becomes increasingly evident with increasing SIL concentrations. (b) The corresponding 2-D GIWAXS images of the neat TT, neat SIL and TT:SIL films. 
Determining crystalline structure and structural parameters of solid-state ionic liquid (SIL) based on GIWAXS data

We define the crystal structure of SIL through 3 steps as follows;

1) Step 1 : We define relations among angles and axes for SIL.

Real space

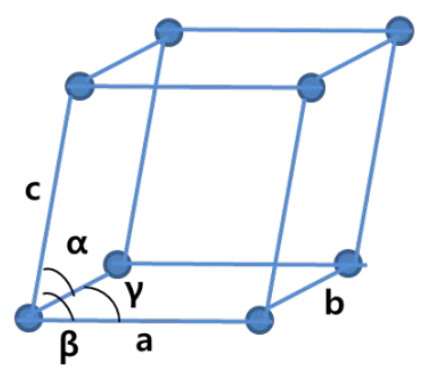

Reciprocal space

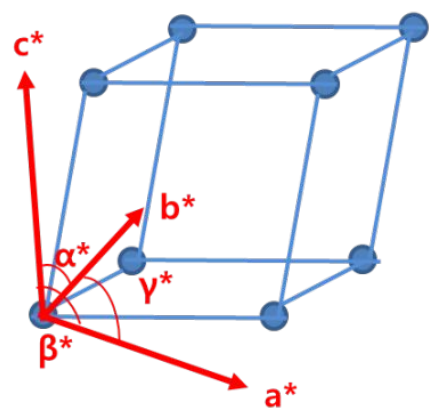

$$
a=2 \pi \frac{b^{*} \times c^{*}}{a^{*} \cdot\left(b^{*} \times c^{*}\right)}, \quad b=2 \pi \frac{c^{*} \times a^{*}}{a^{*} \cdot\left(b^{*} \times c^{*}\right)}, \quad c=2 \pi \frac{a^{*} \times b^{*}}{a^{*} \cdot\left(b^{*} \times c^{*}\right)} \quad \text { where }
$$

$a^{*}=2 \pi / d_{100}=q_{100}, b^{*}=2 \pi / d_{010}=q_{010}, c^{*}=2 \pi / d_{001}=q_{001}$.

Also, we define the angles between the axes as follows;

$$
\begin{aligned}
& \cos (\alpha)=\frac{\cos \left(\beta^{*}\right) \cos \left(\gamma^{*}\right)-\cos \left(\alpha^{*}\right)}{\sin \left(\beta^{*}\right) \cdot \sin \left(\gamma^{*}\right)}, \cos (\beta)=\frac{\cos \left(\gamma^{*}\right) \cos \left(\alpha^{*}\right)-\cos \left(\beta^{*}\right)}{\sin \left(\gamma^{*}\right) \cdot \sin \left(\alpha^{*}\right)}, \\
& \cos (\gamma)=\frac{\cos \left(\alpha^{*}\right) \cos \left(\beta^{*}\right)-\cos \left(\gamma^{*}\right)}{\sin \left(\alpha^{*}\right) \cdot \sin \left(\beta^{*}\right)}
\end{aligned}
$$

where

$$
\begin{aligned}
& \cos \left(\alpha^{*}\right)=\frac{\left(q_{011}{ }^{2}-q_{010}{ }^{2}-q_{001}{ }^{2}\right)}{2 \cdot q_{010} \cdot q_{001}} \cos \left(\beta^{*}\right)=\frac{\left({q_{101}}^{2}-q_{100}{ }^{2}-q_{001}{ }^{2}\right)}{2 \cdot q_{100} \cdot q_{001}}, \\
& \cos \left(\gamma^{*}\right)=\frac{\left(q_{110}{ }^{2}-q_{100}{ }^{2}-q_{010}{ }^{2}\right)}{2 \cdot q_{100} \cdot q_{010}}
\end{aligned}
$$

2) Step 2: We conduct modeling of three possible molecular structures of SIL. 

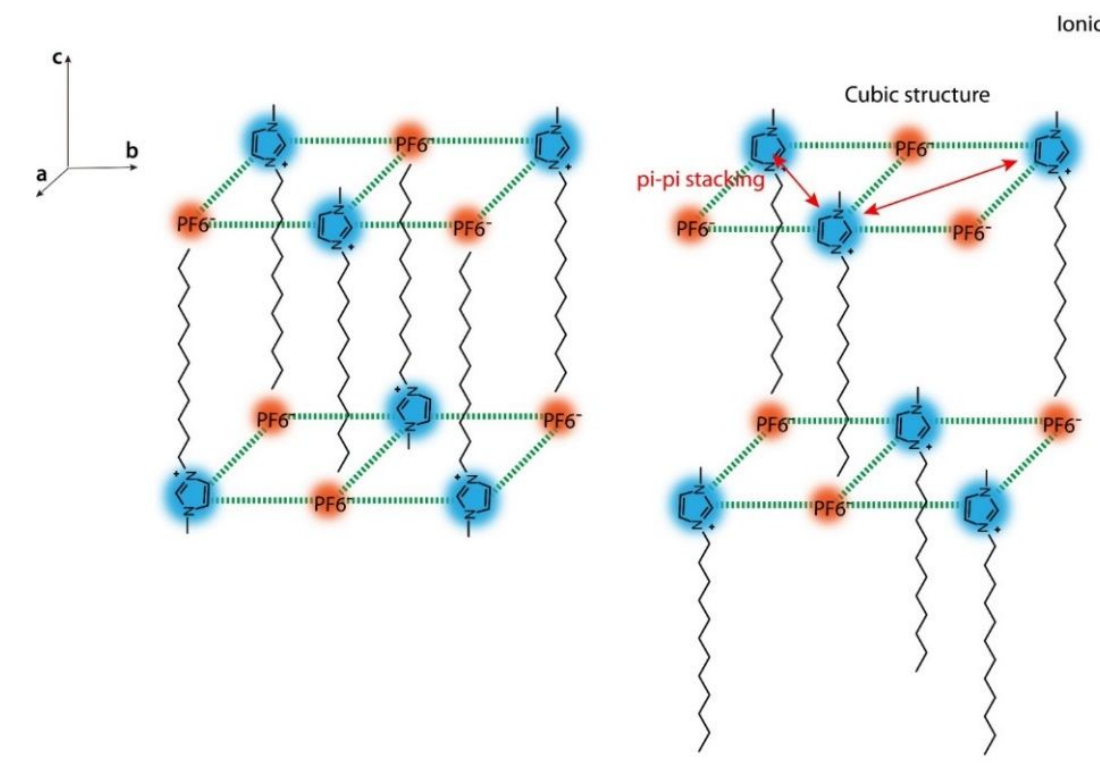

lonic liquid

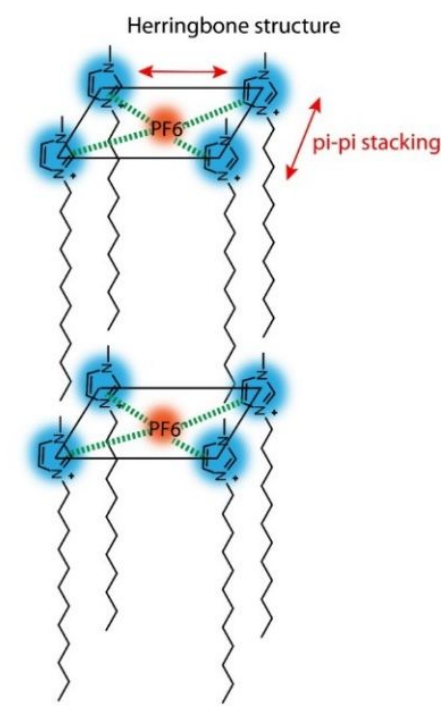

3) Step 3: From the relations, we compare the parameters from modeling with the experimental result from GIWAXS measurement as bellow:

(a)

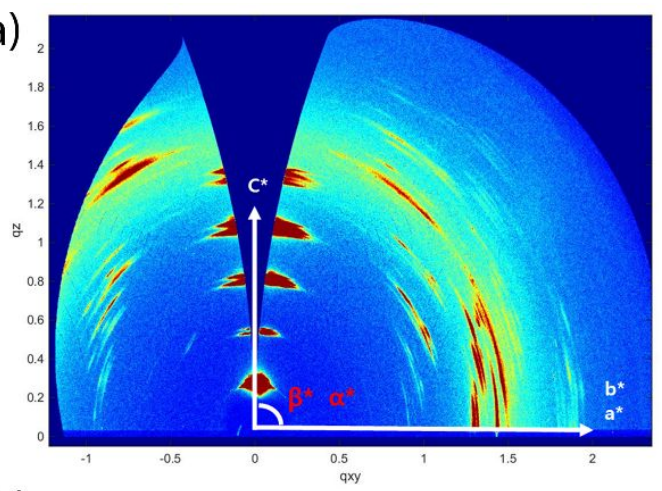

(b) Base-centered monoclinic structure

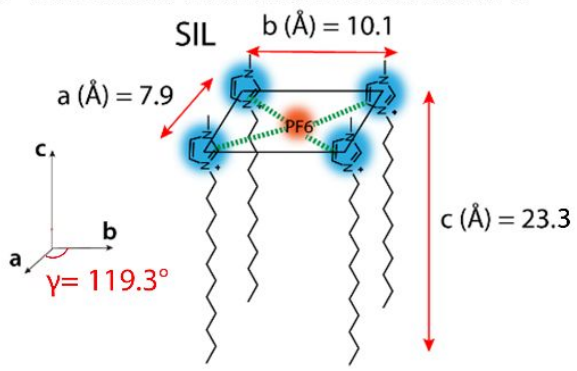

Experimental results

\begin{tabular}{|c|cc}
\hline $\mathrm{q}_{\mathrm{z}}\left(\AA^{-1}\right)$ & $\mathrm{q}_{\mathrm{xy}}\left(\AA^{-1}\right)$ & $\begin{array}{c}\text { Peak } \\
\text { Indexing }\end{array}$ \\
\hline 0.270 & 0 & $(001)$ \\
0 & 1.2624 & $(-120)$ \\
0 & 1.4062 & $(110)$ \\
0 & 1.4267 & $(020)$ \\
0 & 1.608 & $(-210)$ \\
0 & 1.680 & $(-220)$ \\
0 & 1.824 & $(200)$ \\
0 & 2.03 & $(120)$ \\
0 & 2.26 & $(210)$
\end{tabular}

\begin{tabular}{|c|c|}
\hline Parameters & SIL \\
\hline$a(\AA \AA)$ & 7.90 \\
\hline$b(\AA)$ & 10.10 \\
\hline$c(\hat{\AA})$ & 23.27 \\
\hline $\begin{array}{c}\text { Y(deg. }) \\
\text { Unit cell } \\
\text { volume }\end{array}$ & 119.30 \\
\hline
\end{tabular}

Fig. S9. (a) Calculation of the diffraction parameters of the thin-film SIL at room temperature obtained from GIWAXS measurements. (b) Schematic illustration of the base-centered monoclinic structure of the unit cell of the SIL and the lattice parameters of a $(\AA)=7.9, \mathrm{~b}(\AA)$ $=10.1, \mathrm{c}(\AA)=23.27$, and $\gamma\left({ }^{\circ}\right)=119.3$. 

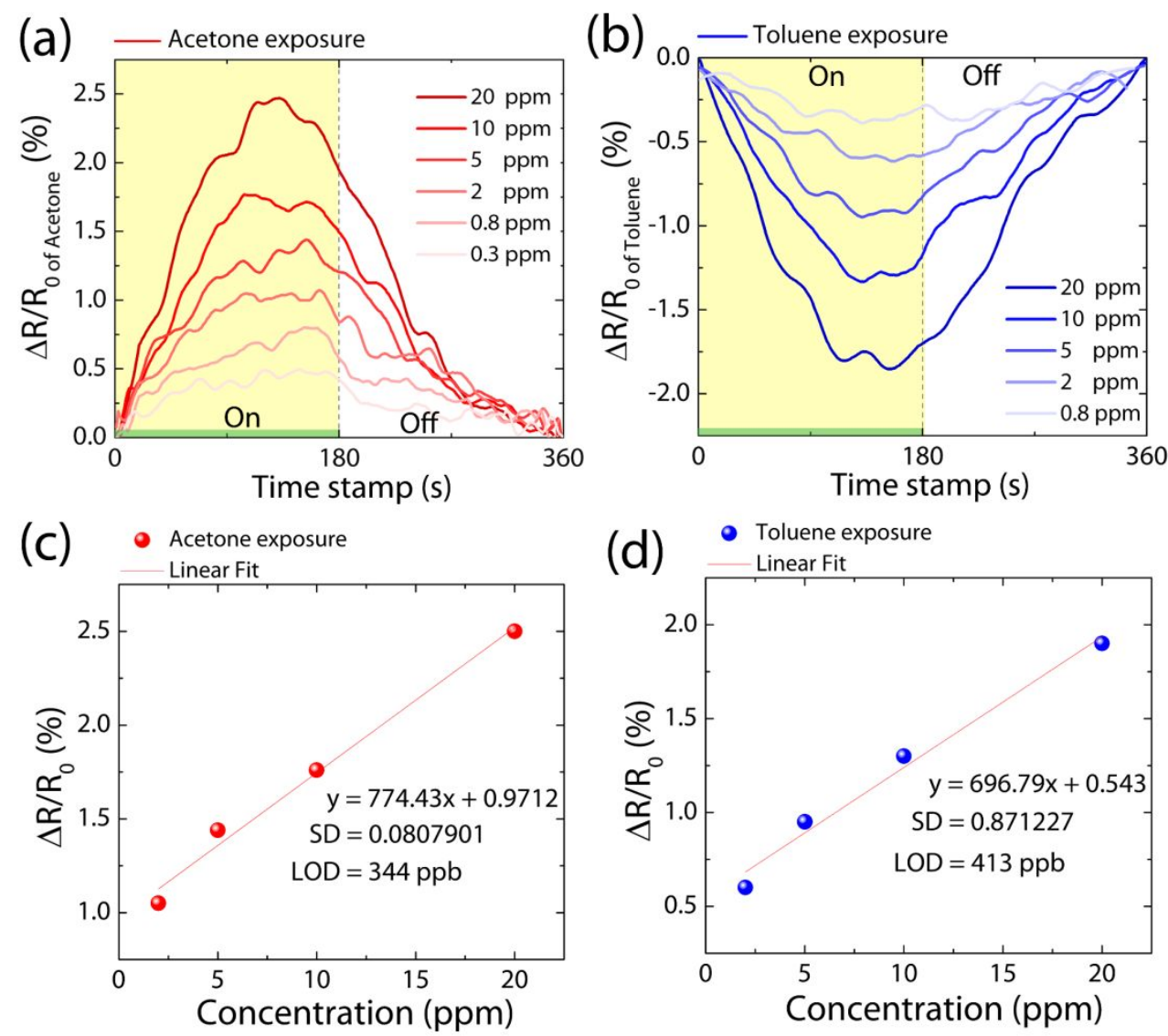

Fig. 10. Sub-ppm-level VOC detection in the TT:SIL TOCs. (a), (b) The sensitivity of TT:SIL $(1: 7 \mathrm{w} / \mathrm{w})$ and $(1: 3 \mathrm{w} / \mathrm{w})$ TOCs upon acetone and toluene exposure, respectively, at low concentrations ranging from $20 \mathrm{ppm}$ to $300 \mathrm{ppb}$. The limits of detection (LODs) of TT:SIL TOCs for (c) acetone and (d) toluene were calculated to be $344 \mathrm{ppb}$ and $413 \mathrm{ppb}$, respectively, using the Inter-national Conference on Harmonization (ICH) model, in which the LOD is defined as $3.3 \times$ (standard deviation/slope of regression line). 